\title{
Amyloid-ß promotes neurotoxicity by Cdk5-induced p53 stabilization
}

Rebeca Lapresa $^{1,2}$, Jesús Agulla ${ }^{3}$, Irene Sánchez-Morán ${ }^{1,2}$, Juan P. Bolaños ${ }^{1,2,4}$; and Angeles Almeida ${ }^{1,2 *}$

${ }^{1}$ Institute of Biomedical Research of Salamanca, University Hospital of Salamanca, University of Salamanca, Calle Zacarías González 2, 37007 Salamanca, Spain

${ }^{2}$ Institute of Functional Biology and Genomics, University of Salamanca, CSIC, Calle Zacarías González 2, 37007 Salamanca, Spain

${ }^{3}$ Institute of Biology and Molecular Genetics, University of Valladolid, CSIC, Calle Sanz y Fores 3, 47003 Valladolid, Spain

${ }^{4}$ CIBERFES, Instituto de Salud Carlos III, Madrid, Spain

Corresponding author:

*Angeles Almeida,

Institute of Biomedical Research of Salamanca

Calle Zacarías González 2, 37007 Salamanca, Spain

Tel. +34923294908; Fax. +34923224876

E-mail: aaparra@usal.es

Running title. Cdk5/p53 mediates $\mathrm{A} ß$ neurotoxicity

Keywords. Amyloid-3/p53/Cdk5/neurodegeneration/Alzheimer's disease 


\section{ABSTRACT}

The p53 tumor suppressor protein, a key regulator of cell apoptosis, has been described to accumulate in affected brain areas from Alzheimer's disease (AD) patients. However, whether p53 plays any role in AD pathogenesis remains unknown. Here, we found that exposure of neurons to oligomers of the amyloidogenic fragment $25-35$ of the $A \beta$ peptide $\left(A \beta_{25-35}\right)$ activated Cdk5, which promoted p53 protein phosphorylation and stabilization. Moreover, $\mathrm{A} \beta_{25-35}$-mediated mitochondrial dysfunction and neuronal apoptosis were prevented by both genetic and pharmacological inhibition of either p53 or Cdk5 activities. To confirm this mechanism in vivo, $\mathrm{A} \beta_{25-35}$ was stereotaxically injected in the cerebral right ventricle of mice, a treatment that caused p53 protein accumulation, dendrite disruption and neuronal death. Furthermore, these effects were prevented in p53 knockout mice or by pharmacologically inhibiting $\mathrm{p} 53$. Thus, $A \beta_{25-35}$ triggers $\mathrm{Cdk5}$ activation to induce $\mathrm{p} 53$ phosphorylation and stabilization, which leads to neuronal damage. Inhibition of the Cdk5-p53 pathway may therefore represent a novel therapeutic strategy against A $\beta$-induced neurodegeneration. 


\section{Introduction}

Alzheimer's Disease (AD) is a complex multifactorial neurodegenerative disease (Selkoe and Hardy, 2016) and the most common form of dementia in the elderly (Winblad et al., 2016). The progressive degeneration of neurons in selective brain regions involved in learning and memory, primarily hippocampus and cortex, results in gradual decline of cognitive function (Selkoe and Hardy, 2016). The main neuropathological hallmarks of AD are the accumulation of abnormally folded amyloid- $\beta$ (A $\beta$ ) peptide and truncated and hyperphosphorylated tau proteins in senile plaques and neuronal tangles, which are causally related to the progression of the neurodegenerative process (Scheltens et al., 2016). According to the widely accepted amyloid cascade hypothesis, the accumulation of $A \beta$ in the brain -derived from the proteolytic processing of the amyloid precursor protein- is a primary triggering factor of $\mathrm{AD}$ pathogenesis as it initiates a molecular cascade of effects leading to neurodegeneration and the subsequent clinical manifestations of dementia (Karran et al., 2011; Selkoe and Hardy, 2016; Winblad et al., 2016). A $\beta$ oligomers appear to be the most neurotoxic species, triggering signaling pathways that involve synaptic dysfunction, $\mathrm{Ca}^{2+}$ homeostasis disruption, oxidative stress, and mitochondrial dysfunction, among others, which culminates in neuronal apoptosis (Green and LaFerla, 2008; Haass and Selkoe, 2007; Jarosz-Griffiths et al., 2016). However, the full underlying mechanism of neuronal apoptosis in response to $A \beta$ is still unknown.

The tumor suppressor protein p53 is a key modulator of cellular responses to genome stress and DNA damage, and p53 activation triggers apoptosis in different cell types, including neurons (Culmsee and Mattson, 2005). Furthermore, numerous evidences demonstrate an increase in 553 level and activity in degenerating neurons, which appears to be a common feature of neurodegenerative diseases (Culmsee and Mattson, 2005; Szybińska and Leśniak, 2017). In particular, enhanced p53 level was detected in brain areas undergoing degeneration 
of AD patients (Hooper et al., 2007; Kitamura et al., 1997) and transgenic animal models of AD (Ohyagi et al., 2005; Szybińska and Leśniak, 2017). Interestingly, p53 expression increases in parallel with intracellular accumulation of $A \beta$ in some degenerating neurons (Ohyagi et al., 2005). However, it is still a matter of debate whether increased levels of p53 in neurons of $\mathrm{AD}$ brains are really implicated in neuronal death or whether they are consequence of the adaptive responses of neurons until apoptosis occurs (Merlo et al., 2014; Sajan et al., 2007; Szybińska and Leśniak, 2017; Zhang et al., 2002). Therefore, the nature of the link between p53 and $\mathrm{AD}$ remains controversial.

Here we study the function of p53 in A $\beta$ neurotoxicity and the underlying mechanism, trying to identify possible therapeutic targets for $\mathrm{AD}$. We found that oligomers of the neurotoxic fragment 25-35 of the $A \beta$ peptide $\left(A \beta_{25-35}\right)$ (Pike et al., 1995) promoted Cdk5-induced $\mathrm{p} 53$ phosphorylation and functional stabilization, both in primary cultured neurons and in vivo, leading to mitochondrial disfunction and neuronal apoptosis. Moreover, we reveal that p53 modulates neuronal susceptibility to $A \beta$ toxicity and determines brain damage, as genetic or pharmacological (PFT $\alpha$ ) inhibition of p53 activity confers resistance to Aß-induced dendrite disruption and neurodegeneration. Hence, the Cdk5-p53 signaling pathway may be the link that couples $\mathrm{A} \beta$ with neuronal apoptosis, providing novel therapeutic targets for AD therapy.

\section{Results}

\section{Amyloid-ß induces p53 stabilization leading to neuronal apoptosis in vitro}

To study the molecular mechanism responsible for $\mathrm{A} ß$ oligomer-induced neurotoxicity, primary cortical neurons were first exposed to increasing concentrations of the amyloidogenic fragment $25-35$ of the $A ß$ peptide $\left(A \beta_{25-35}\right)$ for $24 \mathrm{~h}$ and neuronal apoptosis was measured by flow cytometry. As shown in Fig. 1A, oligomerized $A \beta_{25-35}$ induced neuronal apoptosis in a concentration-dependent manner, reaching the maximum effect at a concentration of $10 \mu \mathrm{M}$, 
which was selected for further experiments. The time-course study revealed that $10 \mu \mathrm{M} A \beta_{25-}$ ${ }_{35}$ caused both neuronal apoptosis (Fig. 1B) and mitochondrial membrane potential $\left(\Delta \psi_{\mathrm{m}}\right)$ depolarization (Fig. 1B). Interestingly, the $\Delta \psi_{\mathrm{m}}$ loss preceded apoptotic death upon the $\mathrm{A} \beta_{25}$ 35 exposure, indicating that mitochondrial dysfunction is cause -not consequence- of the neuronal apoptotic process, thus confirming the importance for $\Delta \psi_{\mathrm{m}}$ maintenance in neuronal survival (Almeida and Bolaños, 2001; Veas-Pérez de Tudela et al., 2015; White and Reynolds, 1996).

Given the well-known function of p53 in regulating mitochondrial function and neuronal apoptosis (Culmsee and Mattson, 2005; Gomez-Sanchez et al., 2011; Rodríguez et al., 2016), we next examined the contribution of p53 to $A \beta_{25-35}$-induced neurotoxicity. We observed an accumulation of p53 protein in neurons from $4 \mathrm{~h}$ of $\mathrm{A} \beta_{25-35}$ exposure (Fig. 1E). However, no increase was observed in p53 mRNA levels (Fig. 1D), revealing that $A \beta_{25-35}$-evoked p53 protein accumulation is because of a post-translational event of $\mathrm{p} 53$. Under cellular stress conditions, p53 protein levels raises immediately because of its stabilization by phosphorylation (Lee et al., 2007). Accordingly, we found that $A \beta_{25-35}$ promoted p53 phosphorylation at Ser15 residue, which correlated with the timing of p53 protein

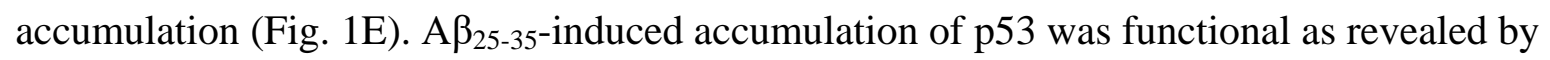
the increase in protein expression of p53 target PUMA, which plays a key role in mitochondrial-mediated apoptosis (Culmsee and Mattson, 2005). Accordingly, $A \beta_{25-35}$ promoted the activation of caspase- 3 at $16 \mathrm{~h}$ of exposure (Fig. 1E), which correlates with the profile of apoptosis induced by A $\beta$ (Fig. 1B). The functional accumulation of p53 was confirmed by the induction of p53 target genes p21 and PUMA (Fig. 1F).

Next, we analyzed the contribution of p53 accumulation to $A \beta_{25-35}$-induced mitochondrial depolarization and neuronal apoptosis by depleting p53 neuronal levels using both small interfering RNA knockdown (sip53) (Fig. EV1A) and gene knockout of p53 (p53 $3^{-1-}$. 
Following 24 h of $A \beta_{25-35}$ exposure, the lack of p53 accumulation in sip53 (Fig. EV1A) and p53/- (Fig. 2B) neurons, which prevented the induction of p53 protein targets, p21 and Bax (Fig. 2B), significantly protected against neuronal apoptosis (Fig. 2A and 2C) and caspase-3 activation (Fig. 2B). Moreover, p53 loss prevented $A \beta_{25-35}$-induced mitochondrial depolarization in neurons (Fig. 2D). Finally, the p53-dependent $A \beta_{25-35}$ neurotoxicity was confirmed by pharmacological inhibition of p53 transcriptional activity with PFT $\alpha$, which decreased $A \beta_{25-35}$-induced neuronal apoptosis in a concentration-dependent manner (Fig. 2E). Furthermore, neuronal protection exerted by PFT $\alpha$ was specific and dependent on p53 activity, as the same effect was observed in $\mathrm{p} 53^{+/+}$and $\mathrm{p} 53^{-/-}$neurons (Fig. 2F). Altogether, these results demonstrate that $A \beta_{25-35}$ promoted p53 phosphorylation and stabilization, which induced the expression of proapoptotic proteins, PUMA and Bax, leading to mitochondrial dysfunction and neuronal apoptosis.

\section{Amyloid-8-induced p53 phosphorylation was mediated by Cdk5 activation}

Once demonstrated that $A \beta$-induced neurotoxicity is dependent on p53 phosphorylation and stabilization, we aimed to identify the kinase involved in the process. It was described that Cdk5, a proline-directed serine/threonine kinase that plays a key role in neuronal degeneration (Maestre et al., 2008; Patrick et al., 1999), phosphorylates p53 on Ser15 under stress conditions, leading to its accumulation (Lee et al., 2007). Cdk5 is persistently activated when bound to its activator p25 (Lee et al., 2000), generated from the $\mathrm{Ca}^{2+}$-dependent proteolytic cleavage of p35 (Kusakawa et al., 2000), that accumulates in the brain of AD patients with Alzheimer's disease (Patrick et al., 1999). As shown in Fig. 3A, A $\beta_{25-35}$ induced the rapid (within $2 \mathrm{~h}$ ) accumulation of p25. Moreover, Cdk5 activity, as determined by histone $\mathrm{H} 1$ phosphorylation, was increased in neuronal extracts exposed to $A \beta_{25-35}$ from $2 \mathrm{~h}$ (Fig. 3B), then confirming that $A \beta_{25-35}$ triggered Cdk5 activation in neurons. Next, we measured 
intracellular free $\mathrm{Ca}^{2+}$ concentrations as it promotes calpain activation and consequently p25 formation from p35 (Kusakawa et al., 2000). $\mathrm{A} \beta_{25-35}$ induced the rise in $\mathrm{Ca}^{2+}$ concentrations in neurons from $\mathrm{p} 53^{+/+}, \mathrm{p} 53^{+/-}$and $\mathrm{p} 53^{-/-}$mice (Fig. 3C). In all cases, this effect was prevented by the N-methyl-d-aspartate (NMDA) receptor inhibitor, MK801, indicating that intracellular $\mathrm{Ca}^{2+}$ influx was mediated by NMDA receptor stimulation. Moreover, $\mathrm{A} \beta_{25-35}$ elicited a similar decrease in $\mathrm{p} 35$ protein abundance and the accumulation of $\mathrm{p} 25$ in both $\mathrm{p} 53^{+/+}$and $\mathrm{p} 53^{+/-}$ neurons (Fig. 3D), indicating that $A \beta_{25-35}$-triggered Cdk5 activation was independent on $\mathrm{p} 53$ levels.

Next, we examined whether Cdk5 activation was responsible for the stabilization of p53 upon $\mathrm{A} \beta_{25-35}$ exposure. As shown in Fig. 3E, Cdk5 knockdown (siCdk5) (Fig. EV1B) prevented p53 accumulation and the induction of PUMA and Bax proteins caused by $\mathrm{A} \beta_{25-35}$, strongly suggesting that Cdk5 increases the stability of the p53 protein. Moreover, knockdown of Cdk5 expression prevented $A \beta_{25-35}$-induced mitochondrial depolarization (Fig. 3F), caspase-3 activation (Fig. 3E), and apoptotic cell death (Fig. 3G) in neurons. The implication of Cdk5 activity on $A \beta_{25-35}$ neurotoxicity was confirmed with the Cdk inhibitor roscovitine, which dose-dependently prevented $A \beta_{25-35}$-caused neuronal apoptosis (Fig. $3 \mathrm{H}$ ). The effects of Cdk5 knockdown (Fig EV1C and Fig. EV1D) and roscovitine (Fig. EV1E) on mitochondrial function and neuronal apoptosis were similar in $\mathrm{p} 53^{+/+}$and $\mathrm{p} 53^{-/-}$neurons. Finally, immunocytochemistry images revealed that both roscovitine and PFT $\alpha$ treatments prevented neuronal apoptosis triggered by $\mathrm{A} \beta_{25-35}$, as shown by the double-staining for the neuronspecific marker Map2 and active caspase-3 (Fig. 3I). Interestingly, we found that p53 accumulated in degenerating neurons, as shown by the co-localization of p53 and active caspase-3 expression, which was prevented by roscovitine treatment (Fig. 3J). These results support the notion that $\mathrm{p} 53$ is phosphorylated by $\mathrm{Cdk} 5$ upon $A \beta_{25-35}$ exposure, leading to $\mathrm{p} 53$ 
stabilization and the induction of pro-apoptotic protein expression, Bax and PUMA, which promoted mitochondrial depolarization and neuronal death.

\section{Amyloid-ß induces p53 stabilization leading to neuronal apoptosis in vivo}

To demonstrate the physiological relevance of our in vitro results, we next aimed to confirm the implication of p53 on $\mathrm{A} ß$ neurotoxicity in vivo. First, we evaluated the stabilization of p53 in the hippocampal and cortical regions, as they are early targets in AD (Selkoe and Hardy, 2016), of the mouse brain after intracerebroventricular injection of oligomerized $A \beta_{25-35}$. We found that $A \beta_{25-35}$ induced the accumulation of p53 (Fig. 4A) and promoted dendrite disruption, as revealed by the decrease in Map2 staining, in both the hippocampus (Fig. 4B) and cortex (Fig. 4C). Moreover, genetic deletion (p53 ${ }^{-1-}$ ) (Fig. EV1F) or pharmacological inhibition (PFT $\alpha$ ) (Fig. 4B and Fig. 4C) of p53 activity significantly improved dendrite disruption induced by $\mathrm{A} \beta_{25-35}$.

Dendrite disruption contributes to the pathology of neurodegenerative disorders, including $\mathrm{AD}$ (Cochran et al., 2014). Once demonstrated the implication of $\mathrm{p} 53$ on $\mathrm{A} \beta_{25-35}$-induced dendrite disruption, we finally studied its possible impact on neurodegeneration. As shown in Fig. 5, double staining of NeuN with TUNEL revealed that $A \beta_{25-35}$-triggered neuronal apoptosis, which was prevented by p53 loss $\left(\mathrm{p} 53^{-1-}\right)$ and inhibition of p53 transactivation activity with PFT $\alpha$ treatment. These in vivo results are consistent with our findings from cultured neurons in vitro and then confirm the relevance of $\mathrm{p} 53$ stabilization on $\mathrm{A} \beta_{25-35^{-}}$ induced neurodegeneration.

\section{Discussion}

Here, we describe a novel signaling pathway responsible for $\mathrm{A} \beta_{25-35}$-induced Cdk5 activation leading to p53 phosphorylation and stabilization, eventually causing mitochondrial 
dysfunction and neuronal apoptosis. Furthermore, we show that this mechanism operates in vivo as either genetic or pharmacological ablation of p53 activity confers resistance against $\mathrm{A} ß$-induced neuronal dendrite disruption and neurodegeneration. This Cdk5-p53 signaling pathway may thus be a causal link coupling $\mathrm{A} \beta$ with neuronal apoptosis.

Mechanistically, it is known that activation of p53 requires a post-translational modification that leads to the stabilization of the protein, which in turn inhibits MDM2-mediated p53 ubiquitination and proteasomal degradation (Lee et al., 2007). In good agreement with this, we found that $A \beta$ treatment caused $\mathrm{p} 53$ phosphorylation and stabilization that induced the expression of mitochondrial proapoptotic proteins PUMA and Bax, and may also directly interacts with mitochondria (Gomez-Sanchez et al., 2011; Green and Kroemer, 2009), causing mitochondrial damage and neurodegeneration. Furthermore, was found that p53 was accumulated in the degenerating neurons, and that loss of p53, or p53 inhibition with PFT $\alpha$, protected these cells against $A ß$ toxicity by preventing the induction of Bax and PUMA, mitochondrial dysfunction and caspase activation. Altogether, these results strongly suggest that p53 accumulation in the brain of AD patients (Hooper et al., 2007; Kitamura et al., 1997) may play a key role on neurodegeneration.

Our data also provides novel insights on the molecular mechanisms of the Cdk5 and p53 interplay. Thus, it is known that Cdk5 binds p53 to induce its phosphorylation, which attenuates MDM2-mediated p53 ubiquitylation, thus inducing nuclear localization and accumulation of the protein (Lee et al., 2007). In addition, p25-induced Cdk5 hyperactivation (Lee et al., 2000; Liu et al., 2015) is known to take place in several neurological disorders including $\mathrm{AD}$, and this has been associated with alterations in neuronal cytoskeleton, synaptic loss and, ultimately, neurodegeneration (Hisanaga and Endo, 2010; Shah and Rossie, 2018). Finally, our previous results showed that NMDA receptor over-stimulation in cortical neurons 
cause p25-mediated Cdk5 hyperactivation (Maestre et al., 2008). Now, we found that A $\beta$ increases NMDA receptor-mediated intracellular $\mathrm{Ca}^{2+}$ levels, leading to $\mathrm{p} 25$ formation (by p35 cleaving), which in turn triggers Cdk5 activation. Notably, our data also show that p53 stabilization upon $A ß$ treatment is a consequence of the formation of the $\mathrm{p} 25 / \mathrm{Cdk} 5$ complex. Intriguingly, elevated levels of both p25 (Patrick et al., 1999; Tseng et al., 2002) and p53 (Hooper et al., 2007; Kitamura et al., 1997) have been detected in the cerebral areas undergoing degeneration in $\mathrm{AD}$ patients, hence suggesting a potential link between Cdk5/p25 and p53 accumulation and AD. Altogether, these results strongly suggest that the mechanism underlying neuronal apoptosis caused by $\mathrm{A} ß$ may occur, at least in part, as a result of a Cdk5mediated p53 stabilization process that leads to the transcriptional activation of mitochondrial-derived proapoptotic proteins.

It has been suggested that the pharmacological prevention of p53-dependent apoptotic cascade activation may represent a novel neuroprotective strategy against sudden injury or chronic disease (Esposito and Cuzzocrea, 2010). In fact, treatment with the p53 inhibitor, PFT $\alpha$, has been shown to reduce neuronal death after traumatic brain injury (Plesnila et al., 2007) and to improve the functional recovery following cerebral ischemia (Luo et al., 2009). Interestingly, PFT $\alpha$ has been shown to reduce kainate-induce excitotoxic death and to prevent mitochondrial and dendrite damage (Neema et al., 2005). In good agreement with these observations, we show that PFT $\alpha$ treatment prevents dendrite disruption and the subsequent neuronal death that follows the intracerebroventricular injection of $A ß$ in mice. Dendrite degeneration and mitochondrial dysfunction are both early pathological events in AD and correlate with cognitive and memory deficits (Cai and Tammineni, 2017). Indeed, mitochondrial energy generation is essential to supporting synaptic function and dendrite integrity (Cai and Tammineni, 2017). Therefore, our data supports the notion that PFT $\alpha$ 
treatment is a promising novel therapeutic strategy against $\mathrm{AD}$ by protecting mitochondrial function and dendrite integrity.

In summary, here we show that $\mathrm{A} \beta$-induced $\mathrm{Cdk} 5$ activation triggers p53 phosphorylation and stabilization, leading to mitochondrial depolarization, dendrite disruption and neuronal death. This suggests that p53 is an attractive therapeutic target for AD treatment and that the p53 inhibitor, PFT $\alpha$, may represent a possible therapeutic tool to delaying neurodegeneration in AD patients.

\section{Materials and Methods}

\section{Primary neuronal culture}

Neuronal cultures were prepared from C57BL/6J and p53 null (p53 ${ }^{-{ }^{-}}$, B6.129S2, The Jackson Laboratories, Sacramento, CA, USA) mouse embryo (E14.5) cortices. Animals were maintained in specific-pathogen free facilities at the University of Salamanca, in accordance with Spanish legislation (RD53/2013) under license from the Spanish government and the European Union (2010/63/EU). Protocols were approved by the Bioethics Committee of the Institute of Biomedical Research of Salamanca. All efforts were made to minimize the numbers of animals used. Neurons were seeded at $1.8 \times 10^{5}$ cells $/ \mathrm{cm}^{2}$ in Neurobasal medium (Invitrogen, Madrid, Spain) supplemented with 2\% B27 (Invitrogen) and 2 mM glutamine (Invitrogen), and incubated at $37^{\circ} \mathrm{C}$ in a humidified $5 \% \mathrm{CO}_{2}$-containing atmosphere. Half of the culture medium was replaced with fresh medium every 3 days. Neurons were used for the experiments on day 9-10 in vitro (Delgado-Esteban et al., 2013).

\section{Neuronal transfections and treatments}


To obtain specific protein knockdown, we used the following small interference RNA (siRNAs; only the forward strand shown): Cdk5, 5'-AAGCCGUACCCGAUGUAUC-3' (corresponding to nucleotides 859-877) (Veas-Pérez De Tudela et al., 2015); p53, 5’CCACUUGAUGGAGAGUAUU-3’' (corresponding to nucleotides 955-973) (DelgadoEsteban et al., 2013). In all cases, a siRNA against luciferase (5'CUGACGCGGAAUACUUCGAUU-3') was used as control siRNA (siControl). Annealed siRNAs were purchased from Dharmacon (Abgene, Thermo Fisher, Epsom, U.K.). Neurons were transfected with siRNA using Lipofectamine RNAiMAX (Invitrogen), following the manufacturer's instructions, and used after 24 (sip53) and 48 (siCdk5) hours. According to the degree of protein knockdown shown in the Supplementary Fig. EV1, the efficiency of transfection of siRNAs is estimated to be $80-85 \%$.

The active truncated amyloid- $\beta$ peptide $A \beta_{25-35}$ (BioNova Cientifica S.L., Madrid, Spain), was dissolved in distilled water at a concentration of $1 \mathrm{mg} / \mathrm{mL}$ and then incubated at $37{ }^{\circ} \mathrm{C}$ for 3 days to induce its oligomerization (Almeida et al., 2005). Neurons were incubated in culture medium containing oligomerized $A \beta_{25-35}(1-25 \mu \mathrm{M})$, during the time periods indicated in the Figures. In parallel, neurons were incubated in the presence of the scramble non-aggregable peptide $A \beta_{35-25}$ (BioNova Cientifica S.L.). When indicated, neurons were incubated in the presence of the Cdk5 inhibitor, roscovitine (2-100 $\mu \mathrm{M}$ Rosc; Sigma), or the p53 transactivation inhibitor, $\mathrm{PFT} \alpha(1-50 \mu \mathrm{M}$; Sigma) for $24 \mathrm{~h}$.

\section{Flow cytometric detection of apoptotic cell death and mitochondrial membrane} potential $\left(\Delta \psi_{m}\right)$

Neurons were carefully detached from the plates using $1 \mathrm{mM}$ EDTA tetrasodium salt in PBS (pH 7.4) at room temperature and neuronal apoptosis and mitochondrial membrane potential $\left(\Delta \psi_{\mathrm{m}}\right)$ was assessed by flow cytometry. Neurons were stained with annexin $\mathrm{V}$ - 
allophycocyanin (APC; Becton Dickinson Biosciences, New Jersey, USA) and 7aminoactinomycin D (7-AAD; Becton Dickinson Biosciences) in binding buffer (100 mM HEPES, $140 \mathrm{mM} \mathrm{NaCl}, 2.5 \mathrm{mM} \mathrm{CaCl}_{2}$ ) to quantitatively determine the percentage of apoptotic neurons by flow cytometry. The annexin V-APC-stained neurons that were 7-AADnegative were considered to be apoptotic. The $\Delta \psi_{\mathrm{m}}$ was assessed using the MitoProbe DilC ${ }_{1}$ $\left(1,1^{\prime}, 3,3,3^{\prime}, 3^{\prime}\right.$ - hexamethylindodicarbo-cyanine iodide) assay kit for flow cytometry (Life Technologies, Eugene, OR, USA), following manufacturer's instructions. Neurons were incubated with the dye at $37^{\circ} \mathrm{C}$, for $30 \mathrm{~min} . \Delta \psi_{\mathrm{m}}$ values were expressed as percentages, using carbonyl cyanide 4-(trifluoromethoxy) phenylhydrazone (CCCP; $10 \mu \mathrm{M})$ for 15 min to define the $0 \% \Delta \psi_{\mathrm{m}}$ value. In all cases, triplicates obtained from four different neuronal cultures were analysed on a FACScalibur flow cytometer (15 mW argon ion laser tuned at $488 \mathrm{~nm}$;

CellQuest software, Becton Dickinson Biosciences) (Gomez-Sanchez et al., 2011).

\section{Quantitative reverse transcription-polymerase chain reaction (RT-qPCR) analysis}

This was performed in total RNA samples, purified from neurons using a commercially available kit (Sigma), using the Power SYBER Green RNA-to-CT ${ }^{\mathrm{TM}}$ 1-Step Kit (Applied Biosystems, Township, USA). Reverse transcription was performed at $48^{\circ} \mathrm{C}$ for $30 \mathrm{~min}$, and PCR conditions were $10 \mathrm{~min}$ at $95^{\circ} \mathrm{C}$ followed by 40 cycles of $15 \mathrm{~s}$ at $95^{\circ} \mathrm{C}$ and $1 \mathrm{~min}$ at $60^{\circ} \mathrm{C}$, using the following forward and reverse primers $(0.3 \mu \mathrm{M})$, respectively (Thermo Scientific): 5'-CAGCAGCGCGTCCACAGAG-3'and 5'-TCCTGATCCAGGCAATCAC-3' (p53 Mmu); 5'-CGAGAACGGTGGAACTTTGAC-3' and 5'-CAGGGCTCAGGTAGACCTTG-3' ( $p 21$, Мmu); 5'-AGCCCAGCAGCACTTAGAGT-3' and 5'-ACTCCTCCTCCTCCACACGCA-3' (PUMA, Mmu); 5'- TCAGCAATGCCTCCTGCACCA-3' and 5'-

GCATGGACTGTGGTCATGAG-3’ (GAPDH Mmu). The mRNA levels of each transcript were normalized to the GAPDH mRNA abundance obtained in the same sample. The relative 
mRNA levels were calculated using the $\Delta \Delta \mathrm{C}_{\mathrm{t}}$ method and were expressed as the fold change between sample and calibrator.

\section{Western blot analysis}

Cells were lysed in RIPA buffer (2\% sodium dodecylsulphate, 2 mM EDTA, 2 mM EGTA and $50 \mathrm{mM}$ Tris $\mathrm{pH}$ 7.5) supplemented with phosphatase inhibitors $\left(1 \mathrm{mM} \mathrm{Na} \mathrm{VO}_{4}\right.$ and 50 $\mathrm{mM} \mathrm{NaF})$ and protease inhibitors $(100 \mu \mathrm{M}$ phenylmethylsulfonyl fluoride, $50 \mu \mathrm{g} / \mathrm{ml}$ antipapain, $50 \mu \mathrm{g} / \mathrm{ml}$ pepstatin, $50 \mu \mathrm{g} / \mathrm{ml}$ amastatin, $50 \mu \mathrm{g} / \mathrm{ml}$ leupeptin, $50 \mu \mathrm{g} / \mathrm{ml}$ bestatin and 50 $\mu \mathrm{g} / \mathrm{ml}$ soybean trypsin inhibitor), stored on ice for $30 \mathrm{~min}$ and boiled for $5 \mathrm{~min}$. Protein concentrations were determined with the BCA (bicinchoninic acid) method, using bovine serum albumin as a standard (BCA Protein Assay kit, Thermo Fisher Scientific). Neuronal extracts were subjected to SDS-polyacrylamide gel (MiniProtean; Bio-Rad). The antibodies used were anti-p53 (1:2000; 2524, Cell Signaling Technology), anti-p(Ser15)-p53 (1:1000; 9286, Cell Signaling Technology); anti-cleaved caspase-3 (1:2000; Asp175, 9661, Cell Signaling), anti-p21 (1:500; 556431, Becton Dickinson Biosciences); anti-p35 (1:500; Sc820, Santa Cruz Biotechnology); anti-Cdk5 (1:750; C-8 Sc-173, Santa Cruz Biotechnology); anti-Bax (1:500; Sc-493, Santa Cruz Biotechnology, Heidelberg, Germany); anti-PUMA (1:1000; ab54288, Abcam, Cambridge, UK); and anti-GAPDH (1:40000; Ambion, Cambridge, UK) overnight at $4^{\circ} \mathrm{C}$. GAPDH was used as loading control. After incubation with horseradish peroxidase-conjugated goat anti-rabbit IgG (Pierce, Thermo Scientific) or goat anti-mouse IgG (Bio-Rad), membranes were incubated with the enhanced chemiluminescence SuperSignal West Dura (Pierce) for 5 min or Immobilon Western Chemiluminiscent HRP Substrate (Merck Millipore; Darmstadt, Germany) for 1 min, before exposure to Kodak XAR-5 film for 1 to $5 \mathrm{~min}$, and the autoradiograms were scanned (VeasPérez De Tudela et al., 2015). 


\section{Cdk5 activity assay}

Neurons were lysed in ice-cold buffer containing $50 \mathrm{mM}$ Tris (pH 7.5), $150 \mathrm{mM} \mathrm{NaCl}, 2 \mathrm{mM}$ EDTA, $1 \%$ NP-40, supplemented with the phosphatase and protease inhibitors cited above. After clearing debris by centrifugation, extracts (200 $\mu \mathrm{g}$ protein) were incubated with antiCdk5 $(1 \mu \mathrm{g})$ for $4 \mathrm{~h}$, at $4^{\circ} \mathrm{C}$, followed by the addition of $30 \mu \mathrm{l}$ of protein A-sepharose (GE Healthcare Life Sciences) for $2 \mathrm{~h}$, at $4^{\circ} \mathrm{C}$. Immunoprecipitates were washed four times in lysis buffer and resuspended in kinase buffer (50 mM Hepes pH 7.5, $10 \mathrm{mM} \mathrm{MgCl}_{2}, 1 \mathrm{mM}$ EDTA and $0.1 \mathrm{mM}$ dithiothreitol) containing $20 \mu \mathrm{M}$ ATP, $2 \mu \mathrm{Ci}$ of $[\gamma-32 \mathrm{P}] \mathrm{ATP}$ and histone $\mathrm{H} 1$ (1 $\mathrm{mg} / \mathrm{ml}$; Sigma). Samples were subjected to SDS-polyacrylamide gel (12\%) electrophoresis and transferred proteins were visualized by autoradiography or blotted with anti-Cdk5 (VeasPérez De Tudela et al., 2015).

\section{Cytosolic $\mathrm{Ca}^{2+}$ determination using Fura-2 fluorescence}

Neurons were loaded with the acetoxymethyl ester form of fura-2/AM ( $2 \mu \mathrm{M}$; Molecular Probes, Eugene, OR, USA) at $37^{\circ} \mathrm{C}$ for $40 \mathrm{~min}$. After loading, neurons were incubated in dyefree standard buffer (140 mM NaCl, $2.5 \mathrm{mM} \mathrm{KCl,} 15 \mathrm{mM}$ Tris-HCl, $5 \mathrm{mM}$ D-glucose, 1.2

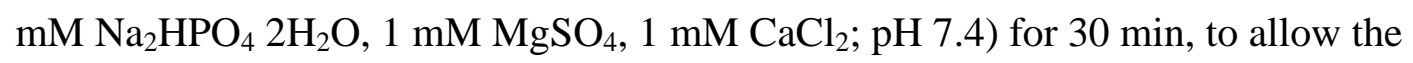
conversion of the dye to its $\mathrm{Ca}^{2+}$-sensitive form. Standard buffer was replaced by experimental buffer $(140 \mathrm{mM} \mathrm{NaCl}, 2.5 \mathrm{mM} \mathrm{KCl}, 15 \mathrm{mM}$ Tris-HCl, $5 \mathrm{mM}$ D-glucose, $1 \mathrm{mM}$ $\left.\mathrm{Na}_{2} \mathrm{HPO}_{4} 2 \mathrm{H}_{2} \mathrm{O}, 1 \mathrm{mM} \mathrm{CaCl} 2 ; \mathrm{pH} 7.4\right)$ and stimuli were applied directly to the neurons. Intracellular-free $\mathrm{Ca}^{2+}$ concentrations were estimated by recording the Fura-2-emitted fluorescence, using a Varioskan Flash (Thermo Fischer, Vantaa, Finland) spectrofluorometer. Neurons were then excited alternatively at 340 and $380 \mathrm{~nm}$, and fluorescence emission was measured at $505 \mathrm{~nm}$. Results are expressed as absolute increase of the ratio of fluorescence 
above the basal (resting) fluorescence (previously normalized to the resting fluorescence) after the addition of stimuli.

\section{Immunocytochemistry}

Neurons grown on glass coverslips were fixed with $4 \%$ (w/v, in PBS) paraformaldehyde for 30 min and immunostained with rabbit anti-cleaved caspase-3 (1:300; Cell Signaling Technology), mouse anti-p53 (1:200; 2524, Cell Signaling Technology) and mouse antiMap2 (1:500; Sigma). Immunolabeling was detected using IgG-Cy2 (1:500) or IgG-Cy3 (1:500) secondary antibodies (Jackson ImmunoResearch Inc.). Nuclei were stained with 6diamidino-2-phenylindole (DAPI, Sigma D9542). Coverslips were washed, mounted with SlowFace light antifade reagent (Invitrogen) and examined under an Olympus IX81 Spinning disk confocal microscope (Olympus®, Tokyo, Japan) (Veas-Pérez de Tudela et al., 2015).

\section{Experimental in vivo model of Amyloid- $\beta$ toxicity by single $\mathbf{A} \boldsymbol{\beta}_{25-35}$ intracerebroventricular injection}

Stereotaxic injections were performed as previously done (Rodríguez et al., 2016). Twelveweek-old wt $\left(\mathrm{p} 53^{+/+}\right)$and $\mathrm{p} 53-\mathrm{KO}\left(\mathrm{p} 53^{-/-}\right)$male mice were anesthetized by inhalatory induction (4\%) and maintained (2.5\%) with sevofluorane (Sevorane; Abbot) in a gas mixture of $70 \% \mathrm{~N}_{2} \mathrm{O}, 30 \% \mathrm{O}_{2}$, using a gas distribution column (Hersill H-3, Madrid, Spain) and a vaporizer (InterMed Penlons Sigma Delta, OX, UK). Mice were placed in a stereotaxic alignment system (Model 1900, David Kopf Instruments, CA, USA) with digital read out (Wizard 550, Anilam, NY, USA) and complemented with a stereomicroscope (Nikon SMZ 645, Tokyo, Japan) and a fiber optic cold light source (Schott KL1500 compact, Mainz, Germany). Injection was performed into the right ventricle at coordinates: $0.22 \mathrm{~mm}$ posterior to bregma, $1 \mathrm{~mm}$ lateral to midline, and $2.5 \mathrm{~mm}$ ventral to dura, using a 5- $\mu$ l Hamilton syringe 
(Microliter 65RN, Hamilton, NV, USA) with a $26 \mathrm{~S}$ needle (type 2 tip). Either $4 \mu \mathrm{L}$ of saline or oligomerized $A \beta_{25-35}(9 \mathrm{nmol})$ were injected using a 5- $\mu \mathrm{L}$ Hamilton syringe with a minipump (UltraMicroPump III, World Precision Instruments, USA) and a digital controller (Micro4 UMC4; World Precision Instruments, USA), at a rate of $0.8 \mu \mathrm{l} / \mathrm{min}$ during $5 \mathrm{~min}$. The syringe was left in place for 10 min before slowly retracting it to allow for $A \beta$ infusion and to prevent reflux. Wounds were sutured, and animals were allowed to recover from anaesthesia in cages placed on a $37^{\circ} \mathrm{C}$ thermostatted plate (Plactronic Digital, 25x60, JP Selecta, Barcelona, Spain). When indicated, animals were intraperitoneally treated with the p53 transactivation inhibitor, Pifithrin $\alpha$ (20 mg/kg; PFT $\alpha$; Sigma), immediately before A $\beta$ injection.

\section{Immunohistochemistry}

Animals were deeply anesthetized by intraperitoneal injection of a mixture (1:4) of xylazine hydrochloride (Rompun; Bayer) and ketamine hydrochloride/chlorbutol (Imalgene; Merial) using $1 \mathrm{~mL}$ of the mixture per kg of body weight, and then perfused intraaortically with $0.9 \%$ $\mathrm{NaCl}$ followed by $5 \mathrm{~mL} / \mathrm{g}$ body weight of Somogy's fixative [4\% (wt/vol) paraformaldehyde, $0.2 \%$ (wt/vol) picric acid in $0.1 \mathrm{M}$ phosphate buffer, $\mathrm{pH} 7.4]$. After perfusion, brains were dissected out sagittally in two parts and postfixed, using Somogy's fixative, for 2 hours at room temperature. Brain blocks were then rinsed successively for $10 \mathrm{~min}, 30 \mathrm{~min}$, and $2 \mathrm{~h}$ with $0.1 \mathrm{M}$ phosphate buffer solution (PBS; pH 7.4) and sequentially immersed in 10, 20, and $30 \%$ (wt/vol) sucrose in PBS until they sank. After cryoprotection, 10, 20 and 40- $\mu$ m-thick sagittal sections were obtained with a freezing-sliding cryostate (Leica; CM1950 AgProtect). The 10 and $20-\mu \mathrm{m}$ sections were placed on microscope slides, whereas the $40-\mu \mathrm{m}$ slices were collected in $0.05 \%$ sodium azide (wt/vol) in $0.1 \mathrm{M}$ PBS. Sections were rinsed in $0.1 \mathrm{M}$ PBS three times each for 10 min and then incubated in: i) 1:1000 anti-NeuN (A-60; Merck 
Millipore), 1:500 anti-Map2 (AP-20; Sigma-Aldrich) or 1:200 anti-p53 (2524, Cell Signaling Technology) in 0.2\% Triton X-100 (Sigma-Aldrich) and 5\% goat serum (Jackson ImmunoResearch) in $0.1 \mathrm{M} \mathrm{PBS}$ for $72 \mathrm{~h}$ at $4{ }^{\circ} \mathrm{C}$; ii) fluorophore-conjugated secondary antibodies (Jackson ImmunoResearch) in $0.05 \%$ Triton X-100 and 2\% goat serum in $0.1 \mathrm{M}$ PBS for $2 \mathrm{~h}$ at room temperature; and iii) $0.5 \mu \mathrm{g} / \mathrm{mL}$ DAPI in PBS for $10 \mathrm{~min}$ at room temperature (Bobo-Jiménez et al., 2017). After rinsing with PBS, sections were mounted with Fluoromount (Sigma) aqueous mounting medium.

Confocal images were taken with a scanning laser confocal microscope ("Spinning Disk" Roper Scientific Olympus IX81) with three lasers 405, 491 y $561 \mathrm{~nm}$ and equipped with $63 \times$ PL Apo oil-immersion objective for high resolution imaging and device digital camera (Evolve; Photometrics, Tucson, USA).

The dendrite integrity in the cortex and hippocampus was assayed by analyzing the density of Map2-positive dendrites in three sections per animal. Fluorescence 8-bit images were acquired as z stacks and were exported into Image $\mathrm{J}$ in tiff format for processing. Images were converted to grayscale 8-bit images and brightness/contrast was adjusted using the ImageJ "auto" function. All Map2-positive dendrites were automatically delineated using the "auto setting threshold" (default method) and "dark background" functions of ImageJ. Thresholded images were subsequently quantified as percent area (area fraction) using the "analyzemeasure" function, which represents the percentage of pixels in the image that have been highlighted (\% area) (Bobo-Jiménez et al., 2017). Values are mean \pm SEM from 15 measurements.

\section{Terminal deoxynucleotidyl transferase dUTP nick end-labeling (TUNEL) assay}

TUNEL assay was performed in $20 \mu \mathrm{m}$ brain sections, following the manufacturer's protocol (Roche Diagnostics, Heidelberg, Germany). Brain sections, fixed as above, were preincubated 
in TUNEL buffer containing $1 \mathrm{mM} \mathrm{CoCl} 2,140 \mathrm{mM}$ sodium cacodylate and $0.3 \%$ Triton X100 in $30 \mathrm{mM}$ Tris buffer, $\mathrm{pH} 7.2$, for $30 \mathrm{~min}$. After incubation at $37^{\circ} \mathrm{C}$ with the TUNEL reaction mixture containing terminal deoxynucleotidyl transferase $(800 \mathrm{U} / \mathrm{ml})$ and nucleotide mixture $(1 \mu \mathrm{M})$ for 90 min, sections were rinsed with PBS and counterstained with Cy3streptavidin (Jackson Immunoresearch Laboratories) (Rodríguez et al., 2016).

\section{Statistical analysis}

Results are expressed as mean \pm S.E.M. A one-way ANOVA with a least significant difference post hoc test was used to compare values between multiple groups, and a twotailed, unpaired Student's t-test was used for two-group comparisons. In all cases, $\mathrm{p}<0.05$ were considered significant. Statistical analyses were performed using SPSS Statistics 24.0 for Macintosh (IBM).

\section{Acknowledgements}

The technical assistances of Lucia Martin, Estefania Prieto, Monica Carabias, Monica Resch and Carmen Castro are acknowledged. The authors are grateful to Bodegas R. López de Heredia Viña Tondonia for funding part of the work. This work was supported by The Instituto de Salud Carlos III (grant numbers PI15/00473; RD16/0019/0018); European Regional Development Fund; Ministerio de Economía y Competitividad (SAF2016-78114R); European Union's Horizon 2020 Research and Innovation Programme (grant agreement 686009); and Junta de Castilla y León (grant number IES007P17). RL was funded by Ministerio de Educación, Cultura y Deporte (FPU fellowship AP2010-3655). ISM was funded by Junta Castilla y León and FSE (EDU/346/2013). 


\section{Contributors}

Rebeca Lapresa, Irene Sánchez-Morán, and Jesus Agulla performed the in vitro experiments and analyzed biochemical data. Rebeca Lapresa and Jesus Agulla performed the in vivo experiments. Juan P Bolaños analyzed data and contributed to design the in vitro experiments. Angeles Almeida supervised the project, designed the experiments, analyzed data, and wrote the manuscript. All authors contributed to the discussion of the results and read, revised and approved the final version of the manuscript.

\section{Conflict of Interest}

The authors declare no conflict of interests. 


\section{References}

Almeida, A., Bolaños, J.P., 2001. A transient inhibition of mitochondrial ATP synthesis by nitric oxide synthase activation triggered apoptosis in primary cortical neurons. J. Neurochem. 77, 676-90.

Almeida, A., Bolaños, J.P., Moreno, S., 2005. Cdh1/Hct1-APC is essential for the survival of postmitotic neurons. J. Neurosci. 25, 8115-8121.

Bobo-Jiménez, V., Delgado-Esteban, M., Angibaud, J., Sánchez-Morán, I., de la Fuente, A., Yajeya, J., Nägerl, U.V., Castillo, J., Bolaños, J.P., Almeida, A., 2017. APC/C Cdh1 Rock2 pathway controls dendritic integrity and memory. Proc. Natl. Acad. Sci. 114, 4513-4518.

Cai, Q., Tammineni, P., 2017. Mitochondrial Aspects of Synaptic Dysfunction in Alzheimer's Disease. J. Alzheimers. Dis. 57, 1087-1103.

Cochran, J.N., Hall, A.M., Roberson, E.D., 2014. The dendritic hypothesis for Alzheimer's disease pathophysiology. Brain Res. Bull. 103, 18-28.

Culmsee, C., Mattson, M.P., 2005. p53 in neuronal apoptosis. Biochem. Biophys. Res. Commun. 331, 761-777.

Delgado-Esteban, M., García-Higuera, I., Maestre, C., Moreno, S., Almeida, A., 2013. APC/C-Cdh1 coordinates neurogenesis and cortical size during development. Nat. Commun. 4, 2879.

Esposito, E., Cuzzocrea, S., 2010. New therapeutic strategy for Parkinson's and Alzheimer's disease. Curr. Med. Chem. 17, 2764-74.

Gomez-Sanchez, J.C., Delgado-Esteban, M., Rodriguez-Hernandez, I., Sobrino, T., Perez de la Ossa, N., Reverte, S., Bolaños, J.P., Gonzalez-Sarmiento, R., Castillo, J., Almeida, A., 2011. The human Tp53 Arg72Pro polymorphism explains different functional prognosis in stroke. J. Exp. Med. 208, 429-37. 
Green, D.R., Kroemer, G., 2009. Cytoplasmic functions of the tumour suppressor p53. Nature $458,1127-1130$.

Green, K.N., LaFerla, F.M., 2008. Linking calcium to Abeta and Alzheimer's disease. Neuron 59, 190-194.

Haass, C., Selkoe, D.J., 2007. Soluble protein oligomers in neurodegeneration: lessons from the Alzheimer's amyloid beta-peptide. Nat. Rev. Mol. Cell Biol. 8, 101-112.

Hisanaga, S., Endo, R., 2010. Regulation and role of cyclin-dependent kinase activity in neuronal survival and death. J Neurochem 115, 1309-1321.

Hooper, C., Meimaridou, E., Tavassoli, M., Melino, G., Lovestone, S., Killick, R., 2007. p53 is upregulated in Alzheimer's disease and induces tau phosphorylation in HEK293a cells. Neurosci. Lett. 418, 34-37.

Jarosz-Griffiths, H.H., Noble, E., Rushworth, J. V., Hooper, N.M., 2016. Amyloid- $\beta$ receptors: The good, the bad, and the prion protein. J. Biol. Chem. 291, 3174-3183

Karran, E., Mercken, M., De Strooper, B., 2011. The amyloid cascade hypothesis for Alzheimer's disease: an appraisal for the development of therapeutics. Nat. Rev. Drug Discov. 10, 698-712.

Kayed, R., Lasagna-Reeves, C.A., 2012. Molecular mechanisms of amyloid oligomers toxicity. Adv. Alzheimer's Dis. 3, 67-78.

Kitamura, Y., Shimohama, S., Kamoshima, W., Matsuoka, Y., Nomura, Y., Taniguchi, T., 1997. Changes of p53 in the brains of patients with Alzheimer's disease. Biochem. Biophys. Res. Commun. 232, 418-421.

Kusakawa, G.I., Saito, T., Onuki, R., Ishiguro, K., Kishimoto, T., Hisanaga, S.I., 2000. Calpain-dependent proteolytic cleavage of the p35 cyclin-dependent kinase 5 activator to p25. J. Biol. Chem. 275, 17166-17172.

Lee, J.-H., Kim, H.-S., Lee, S.-J., Kim, K.-T., 2007. Stabilization and activation of p53 
induced by Cdk5 contributes to neuronal cell death. J. Cell Sci. 120, 2259-2571.

Lee, M.S., Kwon, Y.T., Li, M., Peng, J., Friedlander, R.M., Tsai, L.H., 2000. Neurotoxicity induces cleavage of p35 to p25 by calpain. Nature 405, 360-364.

Liu, S.-L., Wang, C., Jiang, T., Tan, L., Xing, A., Yu, J.-T., 2015. The Role of Cdk5 in Alzheimer's Disease. Mol. Neurobiol. 53, 4328-4342

Luo, Y., Kuo, C.C., Shen, H., Chou, J., Greig, N.H., Hoffer, B.J., Wang, Y., 2009. Delayed treatment with a p53 inhibitor enhances recovery in stroke brain. Ann. Neurol. 65, 520530.

Maestre, C., Delgado-Esteban, M., Gomez-Sanchez, J.C., Bolaños, J.P., Almeida, A., 2008. Cdk5 phosphorylates Cdh1 and modulates cyclin B1 stability in excitotoxicity. EMBO J. $27,2736-2745$.

Merlo, P., Frost, B., Peng, S., Yang, Y.J., Park, P.J., Feany, M., 2014. P53 Prevents Neurodegeneration By Regulating Synaptic Genes. Proc. Natl. Acad. Sci. U. S. A. 111, 18055-18060.

Neema, M., Navarro-Quiroga, I., Chechlacz, M., Gilliams-Francis, K., Liu, J., LaMonica, K., Lin, S.L., Naegele, J.R., 2005. DNA damage and nonhomologous end joining in excitotoxicity: Neuroprotective role of DNA-PKcs in kainic acid-induced seizures. Hippocampus. 15(8):1057-10571.

Ohyagi, Y., Asahara, H., Chui, D.-H., Tsuruta, Y., Sakae, N., Miyoshi, K., Yamada, T., Kikuchi, H., Taniwaki, T., Murai, H., Ikezoe, K., Furuya, H., Kawarabayashi, T., Shoji, M., Checler, F., Iwaki, T., Makifuchi, T., Takeda, K., Kira, J., Tabira, T., 2005. Intracellular Abeta42 activates p53 promoter: a pathway to neurodegeneration in Alzheimer's disease. FASEB J. 19, 255-257.

Patrick, G.N., Zukerberg, L., Nikolic, M., de la Monte, S., Dikkes, P., Tsai, L.-H., 1999. Conversion of $\mathrm{p} 35$ to $\mathrm{p} 25$ deregulates Cdk5 activity and promotes neurodegeneration. 
Nature 402, 615-622.

Pike, C.J., Walencewicz-Wasserman, A.J., Kosmoski, J., Cribbs, D.H., Glabe, C.G., Cotman, C.W., 1995. Structure-activity analyses of beta-amyloid peptides: contributions of the beta 25-35 region to aggregation and neurotoxicity. J. Neurochem. 64, 253-65.

Plesnila, N., von Baumgarten, L., Retiounskaia, M., Engel, D., Ardeshiri, a, Zimmermann, R., Hoffmann, F., Landshamer, S., Wagner, E., Culmsee, C., 2007. Delayed neuronal death after brain trauma involves p53-dependent inhibition of NF-kappaB transcriptional activity. Cell Death Differ. 14, 1529-1541.

Rodríguez, C., Sobrino, T., Agulla, J., Bobo-Jiménez, V., Ramos-Araque, M.E., Duarte, J.J., Gómez-Sánchez, J.C., Bolaños, J.P., Castillo, J., Almeida, A., 2016. Neovascularization and functional recovery after intracerebral hemorrhage is conditioned by the Tp53 Arg72Pro single-nucleotide polymorphism. Cell Death Differ. 24, 1-11.

Sajan, F.D., Martiniuk, F., Marcus, D.L., Frey, W.H., Hite, R., Bordayo, E.Z., Freedman, M.L., 2007. Apoptotic gene expression in Alzheimer's disease hippocampal tissue. Am. J. Alzheimers. Dis. Other Demen. 22, 319-28.

Scheltens, P., Blennow, K., Breteler, M.M.B., de Strooper, B., Frisoni, G.B., Salloway, S., Van der Flier, W.M., 2016. Alzheimer's disease. Lancet. 388, 505-517.

Selkoe, D.J., Hardy, J., 2016. The amyloid hypothesis of Alzheimer's disease at 25 years. EMBO Mol. Med. 8, 595-608.

Shah, K., Rossie, S., 2018. Tale of the Good and the Bad Cdk5: Remodeling of the Actin Cytoskeleton in the Brain. Mol. Neurobiol. 55, 3426-3438

Szybińska, A., Leśniak, W., 2017. P53 Dysfunction in Neurodegenerative Diseases - The Cause or Effect of Pathological Changes? Aging Dis. 8, 506-518.

Tseng, H.C., Zhou, Y., Shen, Y., Tsai, L.H., 2002. A survey of Cdk5 activator p35 and p25 levels in Alzheimer's disease brains. FEBS Lett. 523, 58-62. 
Vaseva, A. V., Moll, U.M., 2009. The mitochondrial p53 pathway. Biochim. Biophys. Acta Bioenerg. 1787, 414-420.

Veas-Pérez De Tudela, M., Maestre, C., Delgado-Esteban, M., Bolaños, J.P., Almeida, A., 2015. Cdk5-mediated inhibition of APC/C-Cdh1 switches on the cyclin D1-Cdk4-pRb pathway causing aberrant S-phase entry of postmitotic neurons. Sci. Rep. 5, 18180.

White, R.J., Reynolds, I.J., 1996. Mitochondrial depolarization in glutamate-stimulated neurons: an early signal specific to excitotoxin exposure. J. Neurosci. 16, 5688-5697.

Winblad, B., Amouyel, P., Andrieu, S., Ballard, C., Brayne, C., Brodaty, H., CedazoMinguez, A., Dubois, B., Edvardsson, D., Feldman, H., Fratiglioni, L., Frisoni, G.B., Gauthier, S., Georges, J., Graff, C., Iqbal, K., Jessen, F., Johansson, G., Jönsson, L., Kivipelto, M., Knapp, M., Mangialasche, F., Melis, R., Nordberg, A., Rikkert, M.O., Qiu, C., Sakmar, T.P., Scheltens, P., Schneider, L.S., Sperling, R., Tjernberg, L.O., Waldemar, G., Wimo, A., Zetterberg, H., 2016. Defeating Alzheimer's disease and other dementias: A priority for European science and society. Lancet Neurol. 15, 455-532.

Zhang, Y., McLaughlin, R., Goodyer, C., LeBlanc, A., 2002. Selective cytotoxicity of intracellular amyloid $\beta$ peptide1-42 through p53 and Bax in cultured primary human neurons. J. Cell Biol. 156, 519-529. 


\section{Figure legends}

Fig. 1. Aß induces p53 stabilization and neuronal apoptosis in vitro. (A) Measurement of neuronal apoptosis (annexin $\mathrm{V}^{+} / 7 \mathrm{AAD}^{-}$neurons) by flow cytometry reveals that the active fragment $A \beta_{25-35}$ caused a dose-dependent increase in neuronal apoptosis at $24 \mathrm{~h}$ of incubation; whereas the inactive $A \beta_{35-25}$ did not affect neuronal survival. (B, $\left.C\right) A \beta_{25-35}(10$ $\mu \mathrm{M})$ exposure results in a time-dependent (B) increase in neuronal apoptosis and (C) mitochondrial depolarization. (D) Time course of p53 mRNA levels measured by RT-qPCR shows that p53 mRNA levels remained unchanged during $A \beta_{25-35}$ exposure. (E) Representative Western blot images showing the time course effect of $A \beta_{25-35}$ on p53 stabilization and phosphorylation (pSer15-p53) and level expression of PUMA and active caspase 3 in neurons. (F) The expression of p53 target genes, p21 and PUMA, were measured by RT-qPCR at $4 \mathrm{~h}$ of $\mathrm{A} \beta_{25-35}$ exposure. Data are expressed as mean \pm SEM from 3-4 different neuronal cultures. ${ }^{*} \mathrm{p}<0.05$ compared to control.

\section{Fig. 2. Stabilization of p53 is involved in Aß-induced neuronal apoptosis in vitro. (A)} Knockdown of p53 by siRNA (sip53) treatment for 2 days significantly decreased $A \beta_{25-35}(10$ $\mu \mathrm{M}$ )-induced neuronal apoptosis (annexin $\mathrm{V}^{+} / 7 \mathrm{AAD}^{-}$neurons), in comparison with control (siControl) neurons. (B) Representative Western blot images showing the effect of genetic depletion of p53 $\left(\mathrm{p} 53^{--}\right)$on the accumulation of p53 and its targets, $\mathrm{p} 21$ and Bax, and the activation of caspase 3 , at $24 \mathrm{~h}$ of $\mathrm{A} \beta_{25-35}$ or $\mathrm{A} \beta_{35-25}(10 \mu \mathrm{M})$ incubation. Flow cytometry analysis shows that genetic deletion of $\mathrm{p} 53\left(\mathrm{p} 53^{-/-}\right)$prevented both $(\mathrm{C})$ neuronal apoptosis and (D) mitochondrial depolarization caused by $10 \mu \mathrm{M} \mathrm{A} \beta_{25-35}$ exposure for $24 \mathrm{~h}$. (E) The inhibitor of p53 transactivation activity, PFT $\alpha$, dose-dependently decreased $\mathrm{A} \beta_{25-35}$-induced neuronal apoptosis. (F) The effect of PFT $\alpha(10 \mu \mathrm{M})$ on $\mathrm{A} \beta_{25-35}$-induced neuronal apoptosis was similar in $\mathrm{p} 53^{+/+}$and $\mathrm{p} 53^{-/-}$mice. Data are expressed as mean \pm SEM from 3-4 different 
neuronal cultures. ${ }^{*} \mathrm{p}<0.05$ compared to control. $\# \mathrm{p}<0.05$ compared to $\mathrm{A} \beta_{25-35}$-treated siControl (A, D) compared to $\mathrm{A} \beta_{25-35}$-treated $\mathrm{p} 53^{+/+}$mice.

\section{Fig. 3. Aß-induced Cdk5 activation triggers p53 accumulation and neuronal apoptosis in}

vitro. Primary cortical neurons were incubated in culture medium in the absence (control) or the presence of oligomerized active $A \beta_{25-35}(10 \mu \mathrm{M})$, which triggered (A) the accumulation of Cdk5 activator p25 and (B) Cdk5 activation from $2 \mathrm{~h}$ of incubation. (C) Neurons from $\mathrm{p} 53^{+/+}$, $\mathrm{p} 3^{+/-}$, and $\mathrm{p} 53^{-/-}$mice were incubated in culture medium and cytosolic free $\mathrm{Ca}^{2+}$ concentrations were measured by fluorimetry before and after NMDA $(100 \mu \mathrm{M})$ and $\beta \mathrm{A}_{25-35}$ $(10 \mu \mathrm{M})$ addition. When the experimental condition $\mathrm{A} \beta_{25-35}+\mathrm{MK} 801$ was assayed, the culture medium contained MK801 (10 $\mu \mathrm{M})$. (D) The formation of $\mathrm{p} 25$ from $\mathrm{p} 35$ induced by $\mathrm{A} \beta_{25-35}$ at $4 \mathrm{~h}$ of incubation was not altered by the genetic depletion of p53 $\left(\mathrm{p} 53^{-1-}\right)$. (E-G) Neurons were transfected with siRNA against Cdk5 (siCdk5) or luciferase (siControl) for $48 \mathrm{~h}$ and then exposed to $A \beta_{25-35}(10 \mu \mathrm{M})$ for further $24 \mathrm{~h}$. (E) Representative Western blot images reveals that knockdown of Cdk5 (siCdk5) prevented the accumulation of p53 and its targets, Bax and PUMA, and the activation of caspase 3 induced by $A \beta_{25-35}$. Knockdown of Cdk5 (siCdk5) prevented $(F)$ mitochondrial depolarization and $(G)$ neuronal apoptosis induced by $A \beta_{25-35}$. (H) The inhibitor of Cdk5 activity, roscovitine, dose-dependently decreased $\mathrm{A} \beta_{25-35}$-induced neuronal apoptosis. (I) Treatment with PFT $\alpha(10 \mu \mathrm{M})$ and roscovitine $(25 \mu \mathrm{M})$ prevented the accumulation of active caspase 3 in neurons exposed to $A \beta_{25-35}$ for $24 \mathrm{~h}$, as revealed by immunocytochemistry (Map2, green; active caspase 3, red; DAPI, blue). (J) A $\beta_{25-35}$ induces p53 accumulation in degenerating neurons, as revealed by the co-localization of p53 and active caspase 3 staining, which was prevented by PFT $\alpha$ and roscovitine treatments. Bar: 20 $\mu \mathrm{m}$. Data are expressed as mean \pm SEM from 3 different neuronal cultures. ${ }^{*} \mathrm{p}<0.05$ compared to control; $\# \mathrm{p}<0.05$ compared to $\beta \mathrm{A}_{25-35}$-treated siControl. 
Fig. 4. Aß-induced p53 accumulation promotes dendrite disruption in vivo. Intracerebroventricular stereotactic injections of 9 nmol A $\beta_{25-35}$ were performed into 12-weekold $\mathrm{p} 53^{+/+}$and $\mathrm{p} 53^{-/-}$male mice. When indicated, mice were intraperitoneally treated with 20 $\mathrm{mg} / \mathrm{kg}$ PFT $\alpha$. (A) Representative images show that $\mathrm{A} \beta_{25-35}$ promoted the accumulation of $\mathrm{p} 53$ in neurons, as revealed by co-immunostaining for the neuronal marker NeuN and p53 in both the hippocampus (CA1 layer) and cortex (Bar scale: $10 \mu \mathrm{m}$; NeuN, green; p53, red; DAPI, blue). (B, C) Representative images show that $A \beta_{25-35}$ promoted dendrite disruption, as revealed by the decrease in Map2 staining in both hippocampus (B) and cortex (C), which was prevented by genetic depletion $\left(\mathrm{p} 53^{--}\right)$and pharmacological inhibition (PFT $\alpha$ ) of p53 activity (Bar scale: $20 \mu \mathrm{m}$; Map2, green; DAPI, blue). Data are expressed as mean \pm SEM from 15 different measurements. ${ }^{*} \mathrm{p}<0.05$ compared to $\mathrm{p} 53^{+/+}$control; $\# \mathrm{p}<0.05$ compared to $\beta \mathrm{A}_{25-35}$-treated $\mathrm{p} 53^{+/+}$mice.

\section{Fig. 5. Genetic and pharmacological inhibition of p53 activity prevented AB-induced} neurodegeneration in vivo. Intracerebroventricular stereotactic injections of 9 nmol A $\beta_{25-35}$ were performed into 12 -week-old $\mathrm{p} 53^{+/+}$and $\mathrm{p} 53^{-/-}$male mice. When indicated, mice were intraperitoneally treated with $20 \mathrm{mg} / \mathrm{kg}$ PFT $\alpha$. (A, B) Representative images showing that $\mathrm{A} \beta_{25-35}$ promoted neuronal apoptosis, as revealed by the double staining of NeuN with TUNEL, in both (A) hippocampus and (B) cortex. Quantification of TUNEL ${ }^{+}$and $\mathrm{NeuN}^{+}$ cells reveals that genetic depletion ( $\left.\mathrm{p} 53^{-/-}\right)$and pharmacological inhibition (PFT $\left.\alpha\right)$ of $\mathrm{p} 53$ activity prevented $\mathrm{A} \beta_{25-35}$-induced neurodegeneration (Bar scale: $20 \mu \mathrm{m}$; NeuN, green; TUNEL, red; DAPI, blue). Data are expressed as mean \pm SEM from 15 different measurements. ${ }^{*} \mathrm{p}<0.05$ compared to $\mathrm{p} 53^{+/+}$control; $\# \mathrm{p}<0.05$ compared to $\beta \mathrm{A}_{25-35}$-treated p53 $3^{+/+}$mice. 
Figure 1 - Lapresa et al

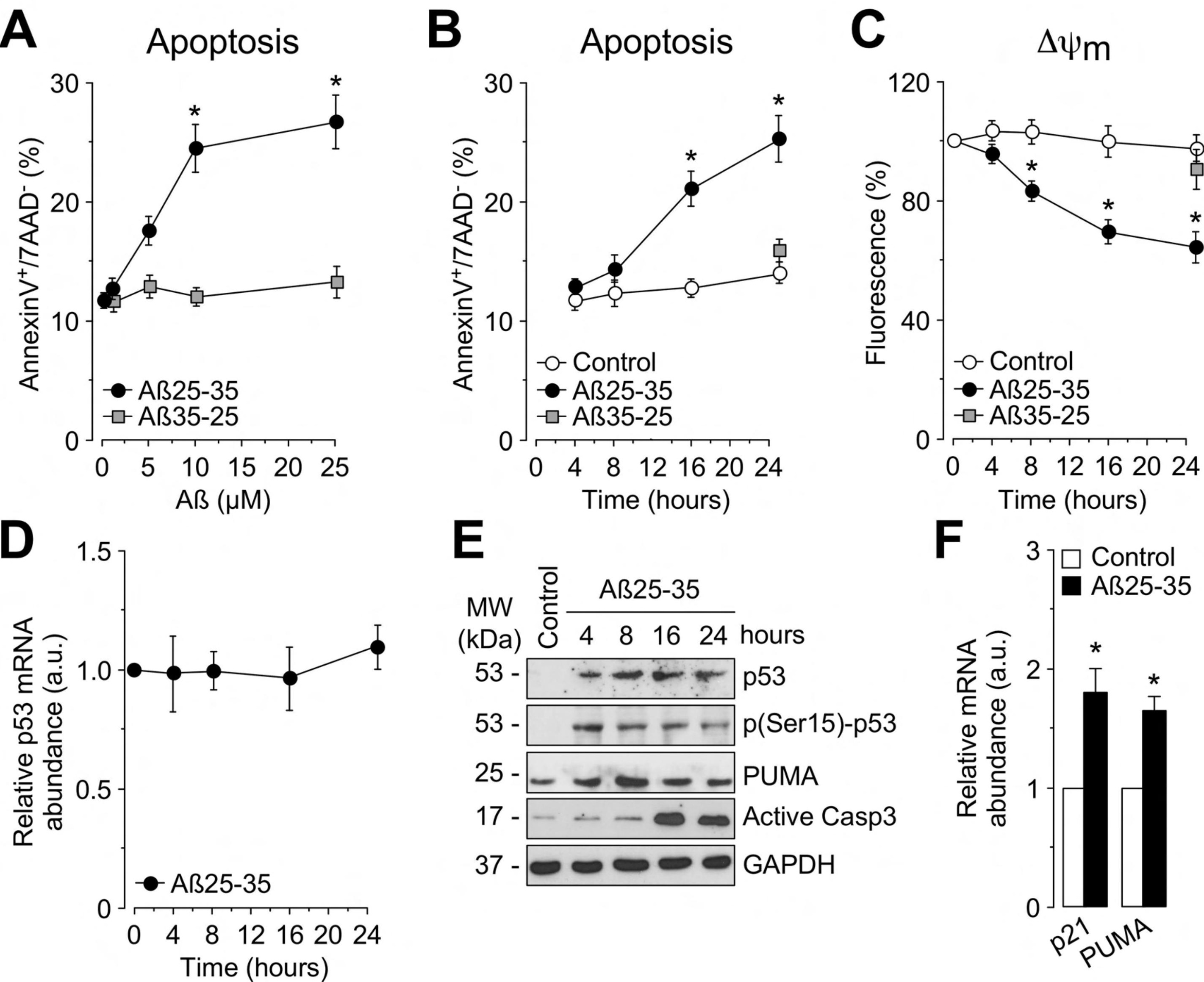


A Apoptosis
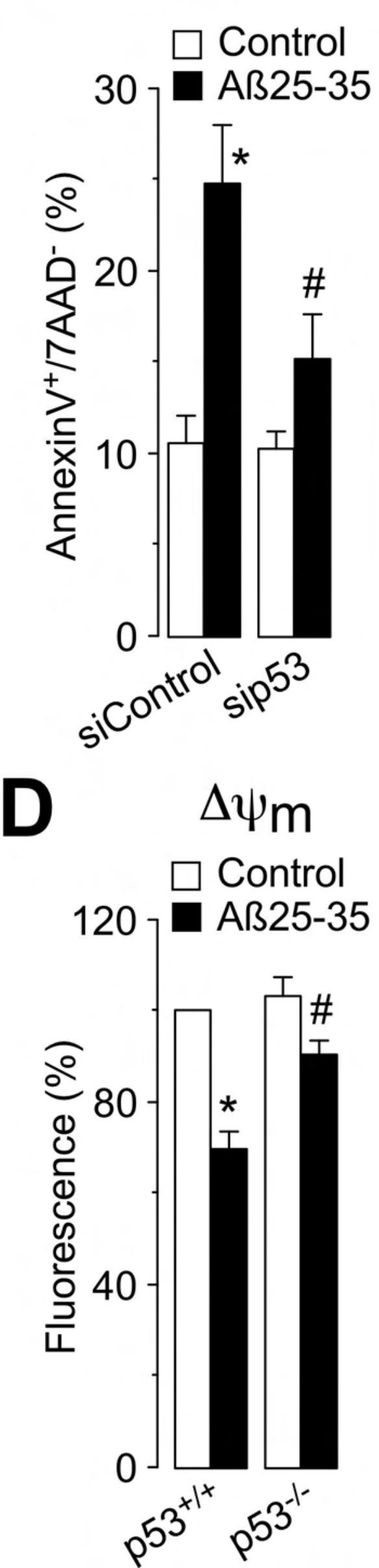

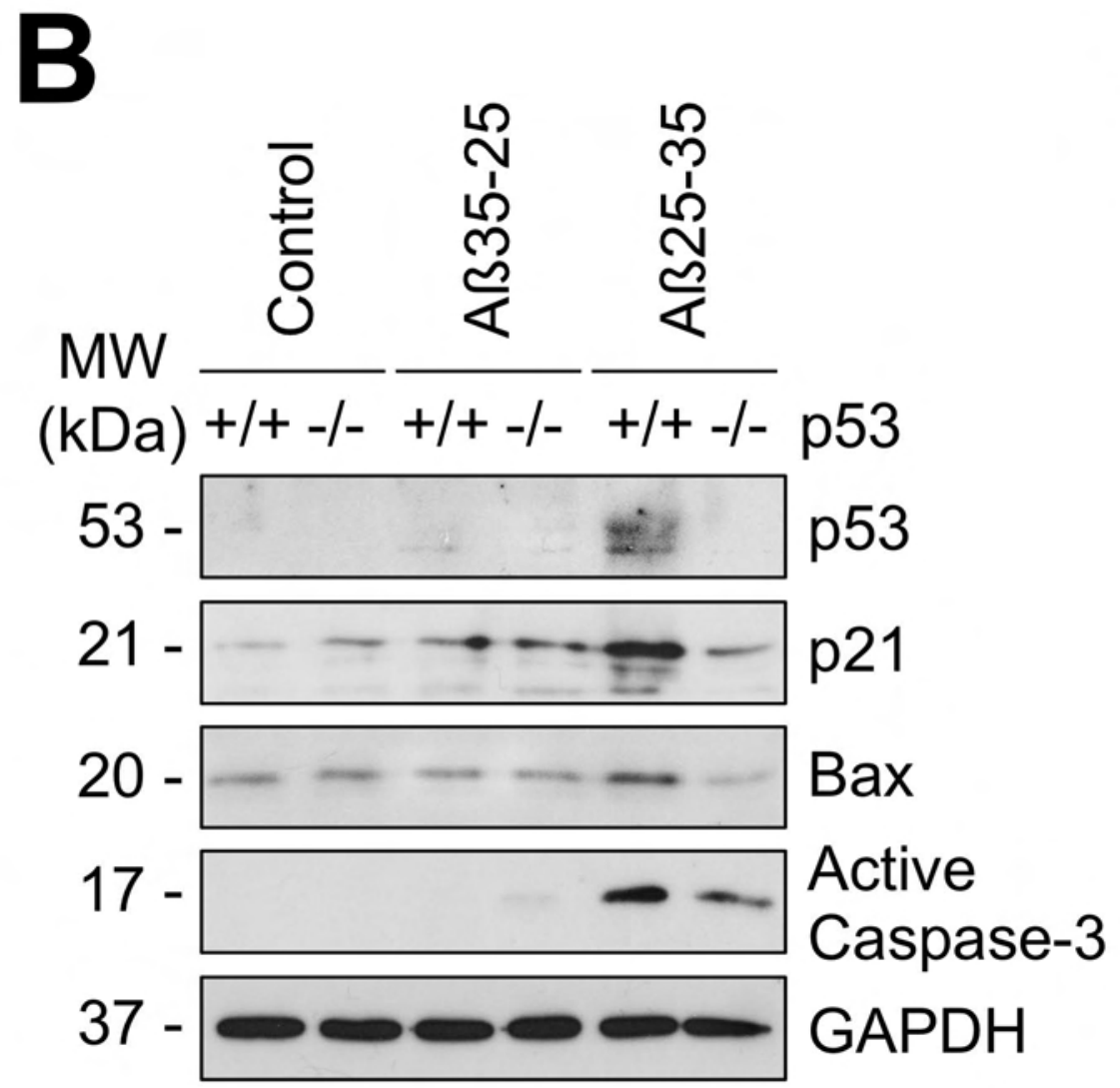

Apoptosis

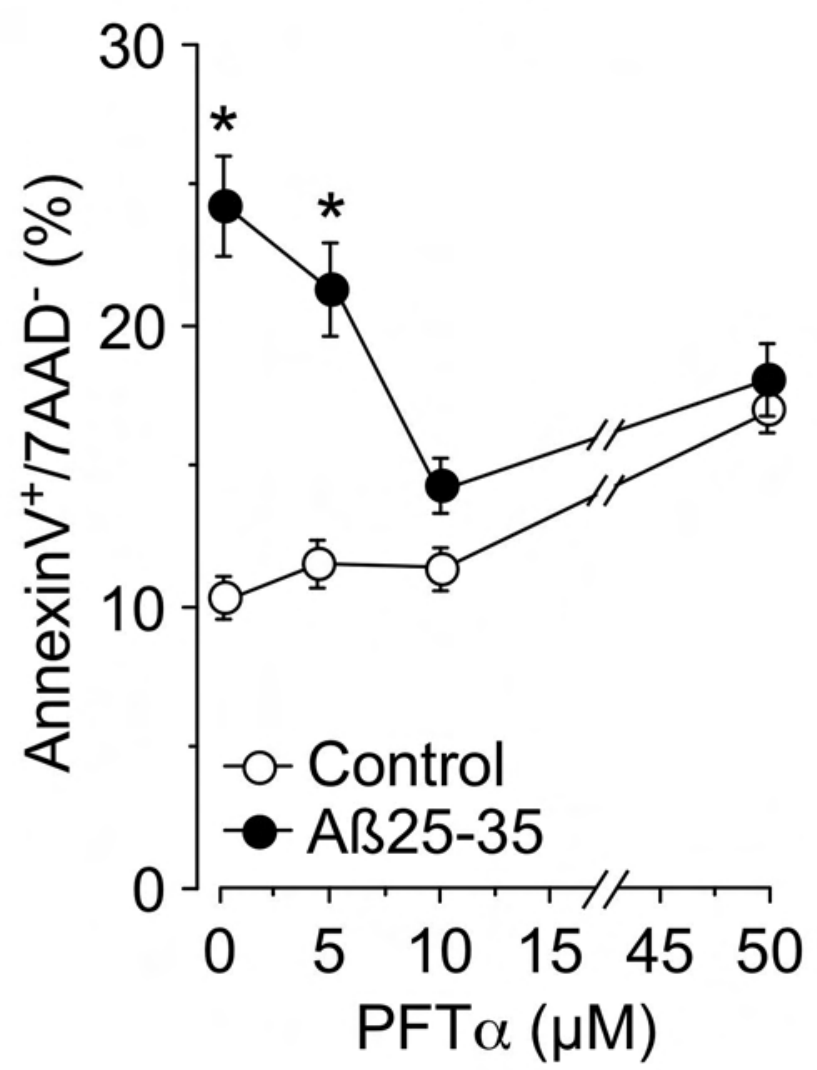

Apoptosis

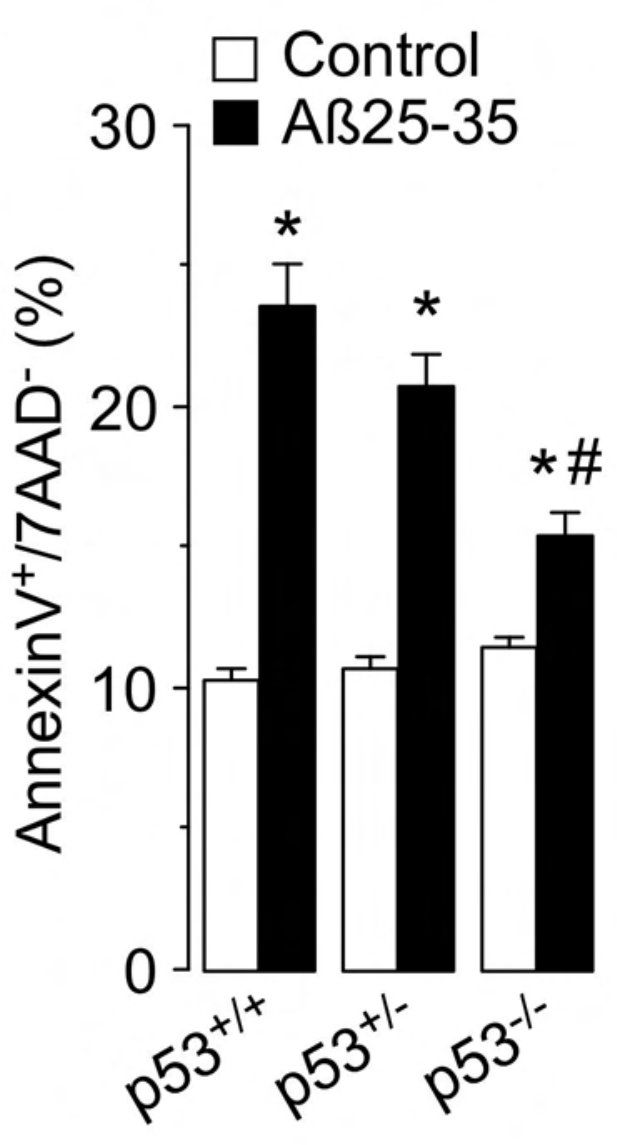

Apoptosis
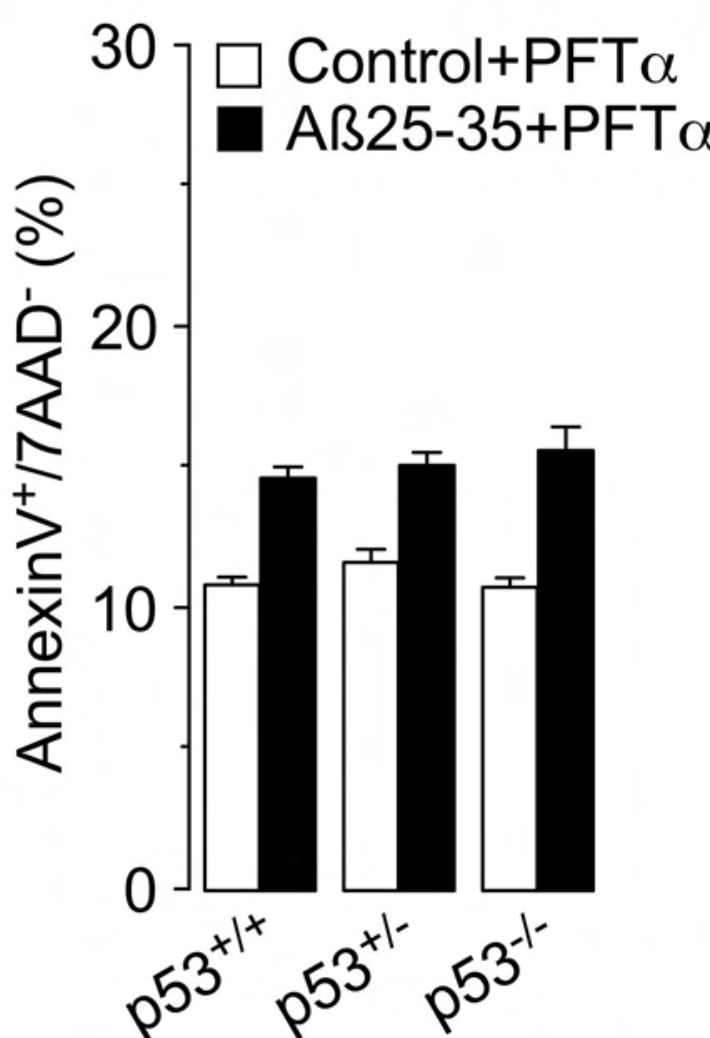
Figure 3 - Lapresa et al

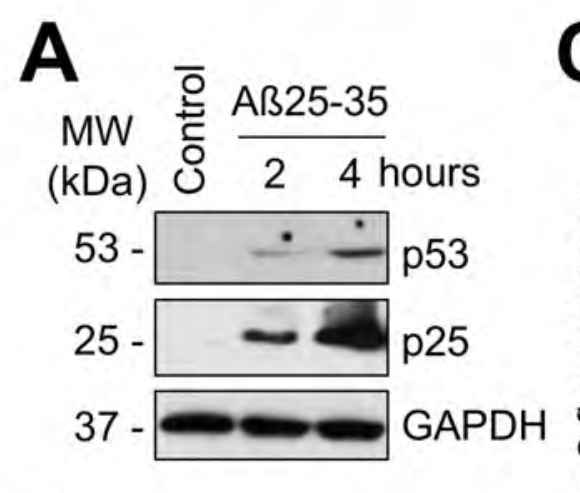

\section{B Cdk5 activity}
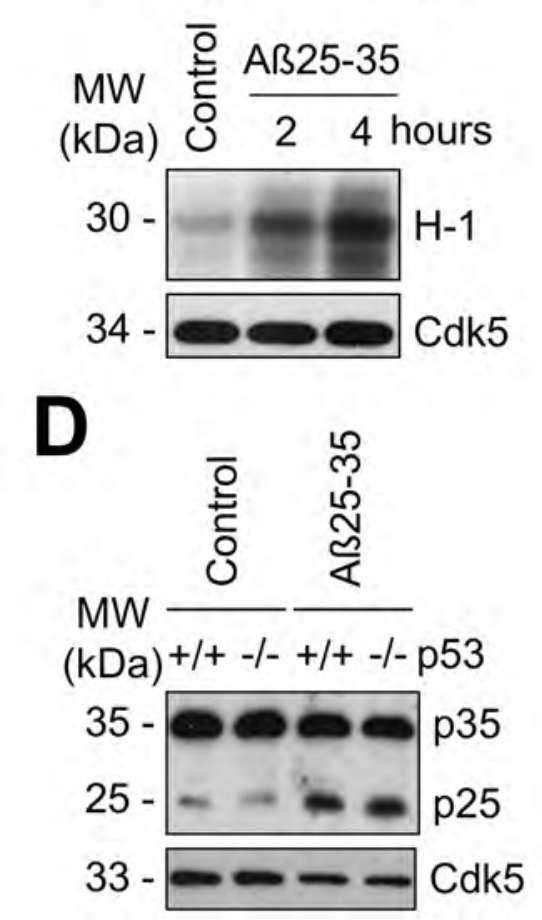

H

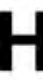

C

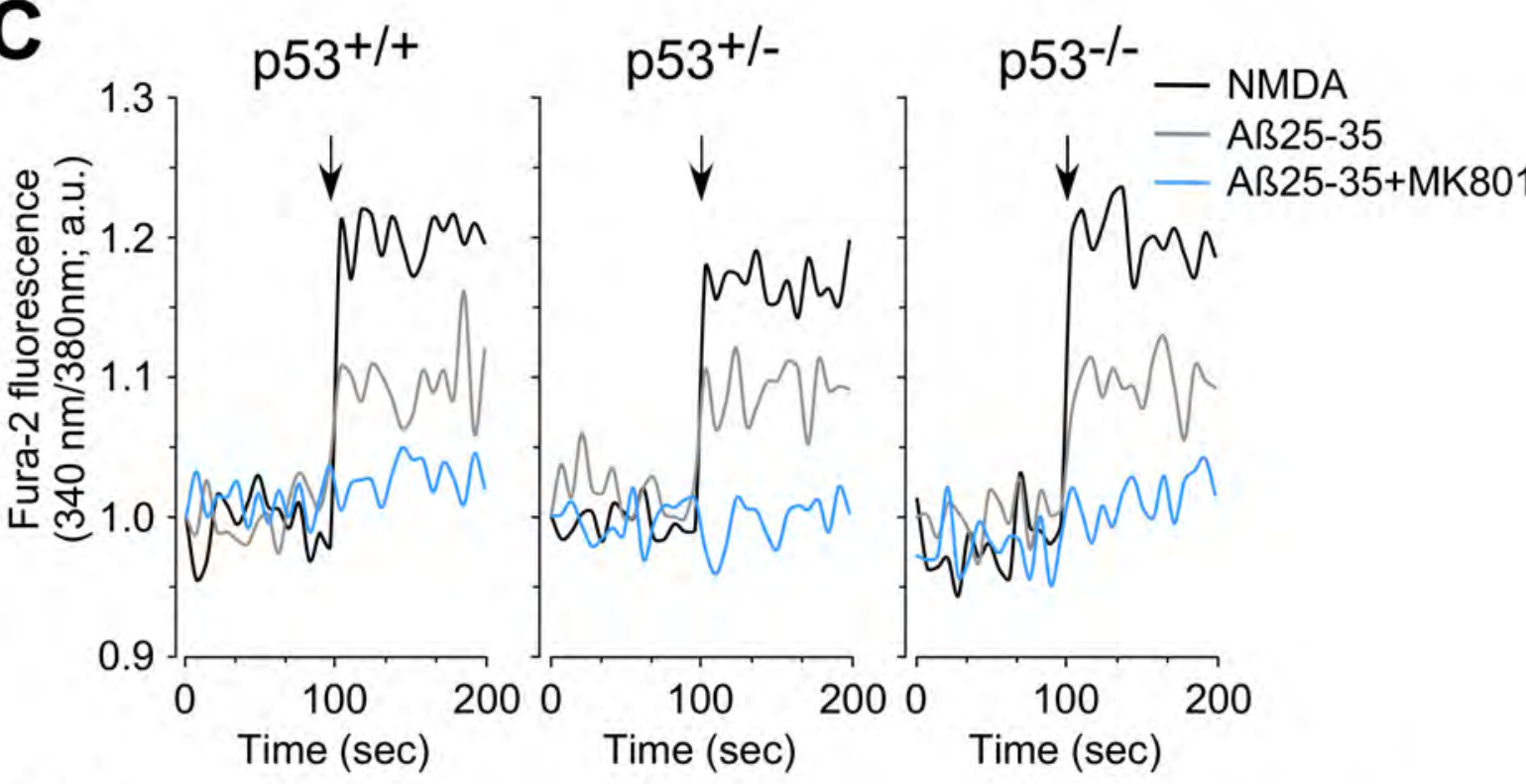

F

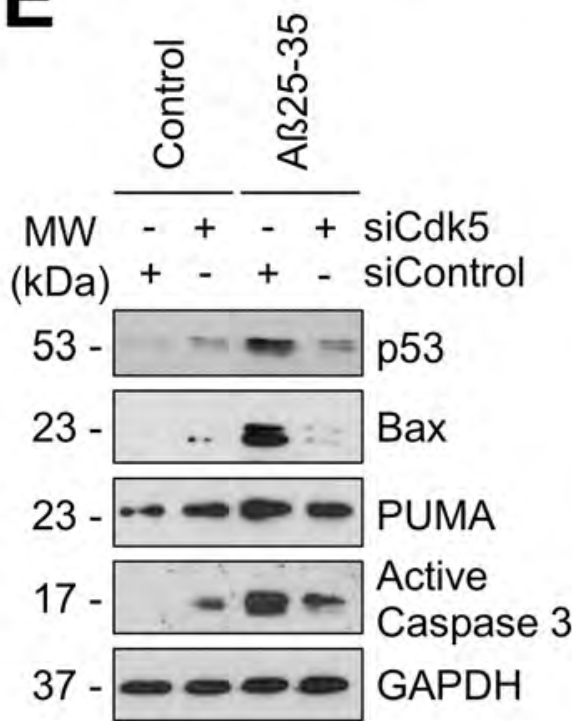

$\Delta \psi_{\mathrm{m}}$

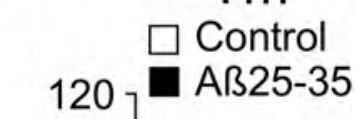

G Apoptosis

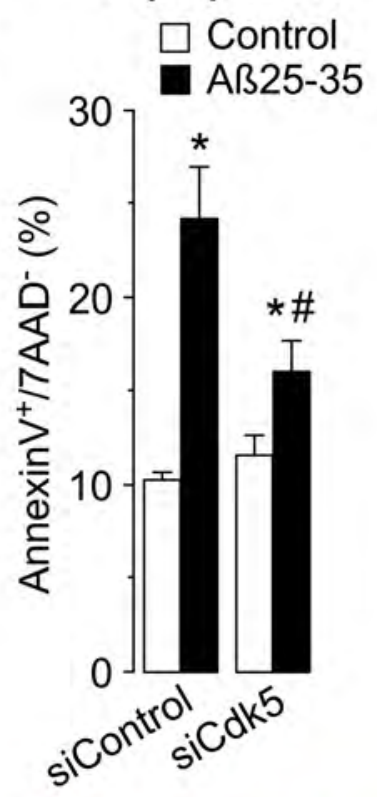

Apoptosis

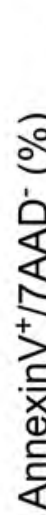

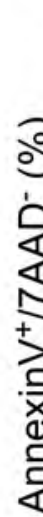

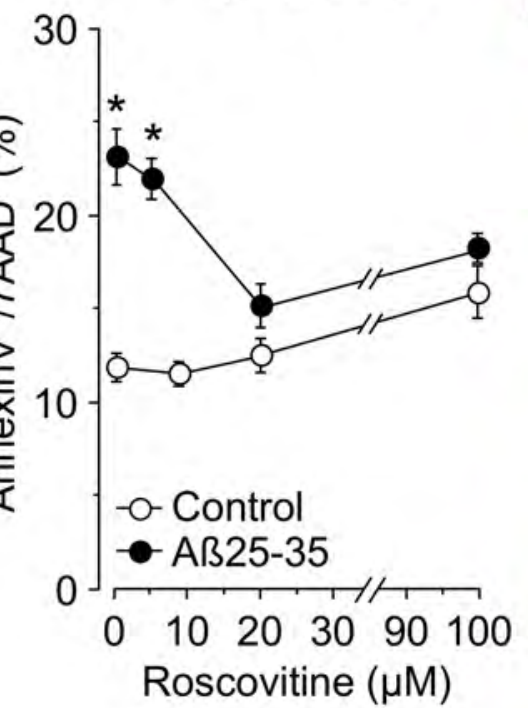

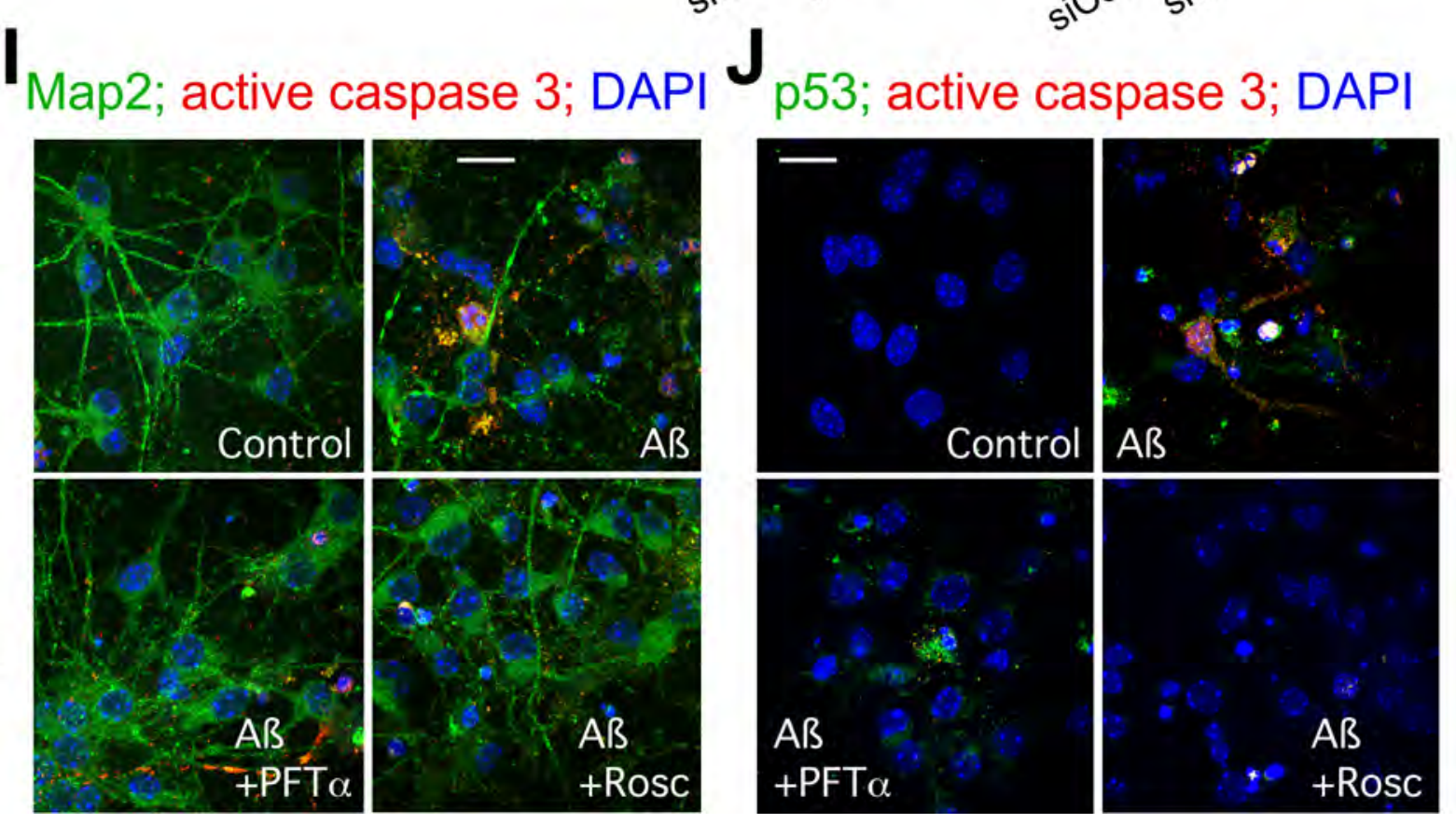


Figure 4 - Lapresa et al

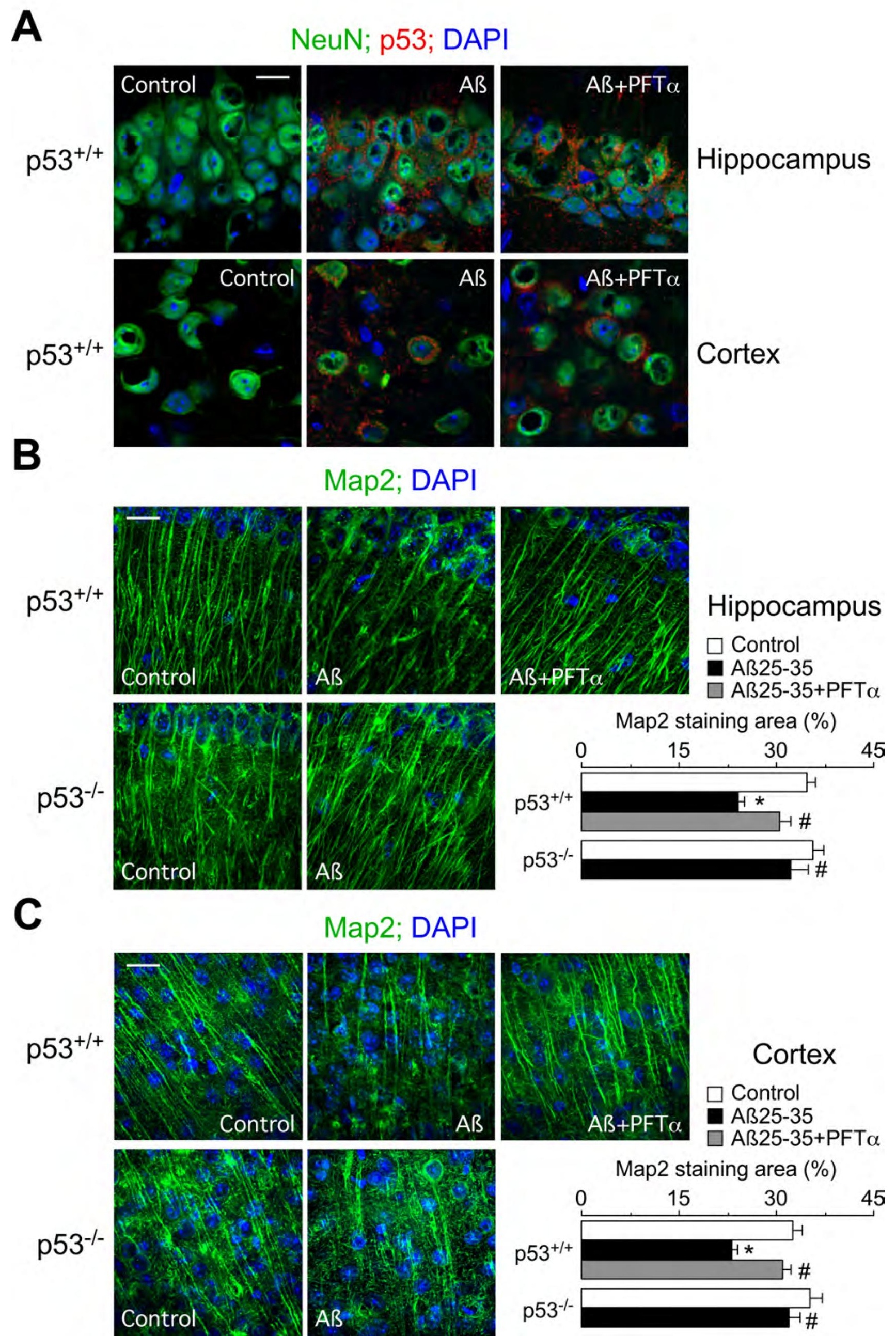




\section{Figure 5 - Lapresa et al}

\section{NeuN; TUNEL; DAPI}
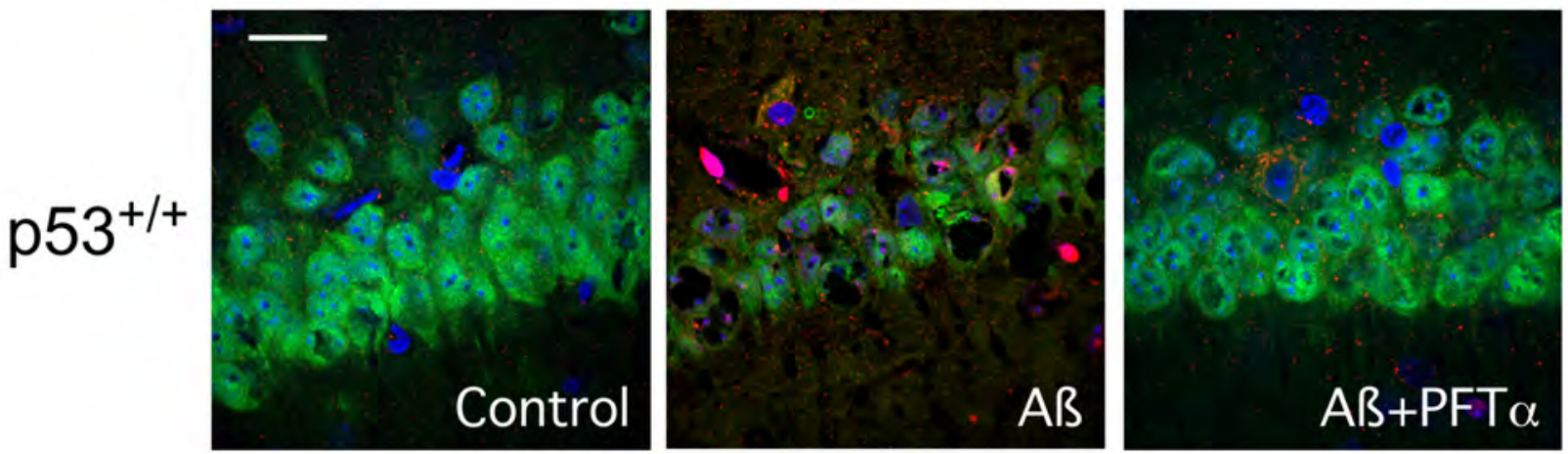

Hippocampus

$\square$ Control

- Aß25-35

$\square \mathrm{A} ß 25-35+\mathrm{PFT} \alpha$

TUNEL ${ }^{+} \mathrm{NeuN}^{+}$cells $/ \mathrm{mm}^{2}$

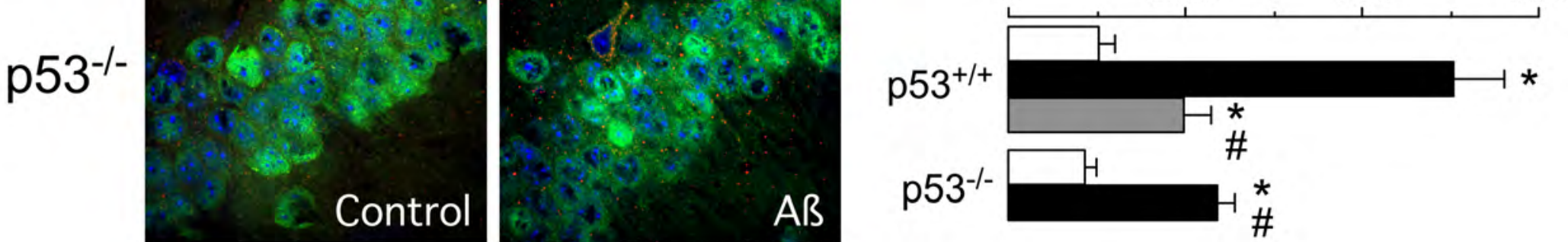

\section{NeuN; TUNEL; DAPI}
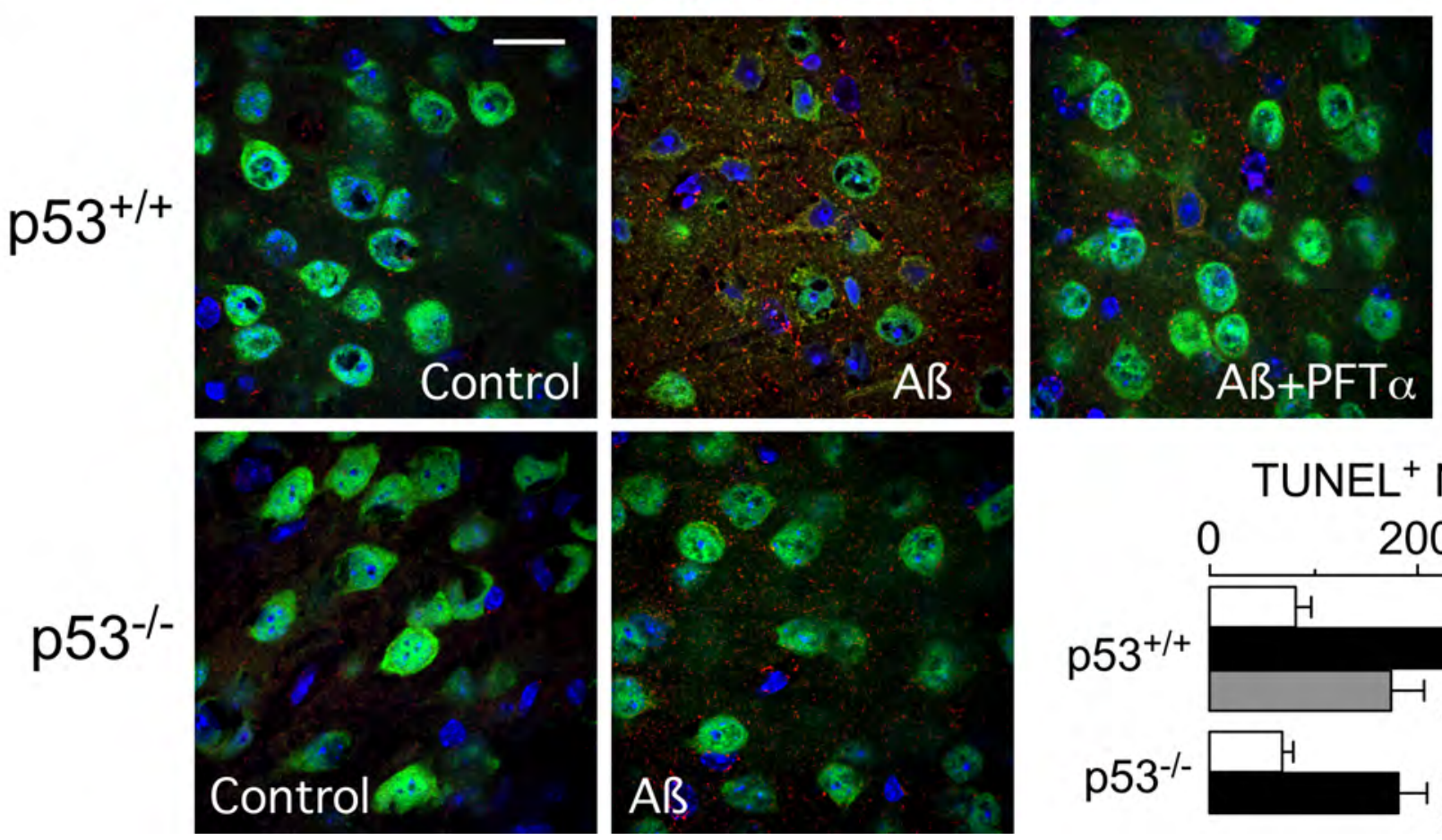

\section{Cortex}
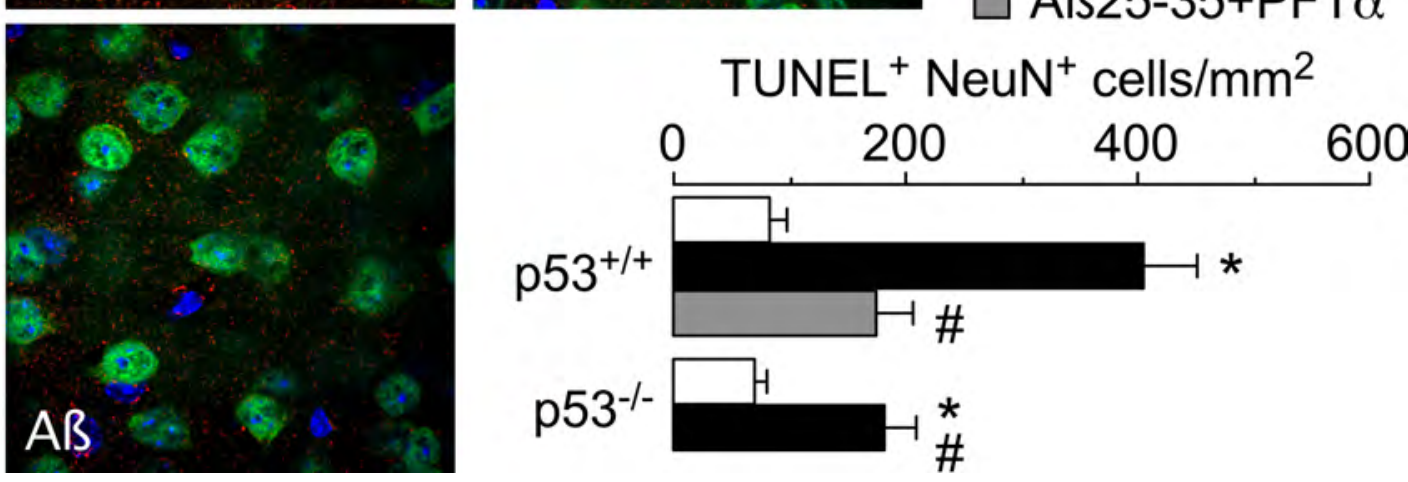